\title{
The Effect of the Presence of Very Cohesive Geldart C Ultra-Fine Particles on the Fluidization of Geldart A Fine Particle Beds
}

\author{
Abbas Kamranian Marnani ${ }^{1, *}$, Andreas Bück ${ }^{2}$, Sergiy Antonyuk ${ }^{3}$, Berend van Wachem ${ }^{1}$, \\ Dominique Thévenin ${ }^{4}\left(\mathbb{D}\right.$ and Jürgen Tomas ${ }^{1,+}$ \\ 1 Institute of Mechanical Process Engineering, Otto von Guericke University (OvGU), Universitätsplatz 2, \\ 39106 Magdeburg, Germany; berend.vanwachem@ovgu.de (B.v.W.); juergen.tomas@ovgu.de (J.T.) \\ 2 Institute of Particle Technology (LFG), Friedrich-Alexander-University Erlangen-Nürnberg, Cauerstraße 4, \\ 91058 Erlangen, Germany; andreas.bueck@fau.de \\ 3 Institute of Particle Process Engineering, Technische Universität Kaiserslautern, Gottlieb-Daimler Street, \\ 67663 Kaiserslautern, Germany; sergiy.antonyuk@mv.uni-kl.de \\ 4 Institute of Fluid Dynamics and Thermodynamics, OvGU, Universitätsplatz 2, 39106 Magdeburg, Germany; \\ dominique.thevenin@ovgu.de \\ * Correspondence: abbas.kamranian@st.ovgu.de; Tel.: +49-391-675-4823 \\ + Passed away. He has initiated and supervised the project.
}

Received: 27 November 2018; Accepted: 5 January 2019; Published: 11 January 2019

\begin{abstract}
The effect of the presence of ultra-fines $(d<10 \mu \mathrm{m})$ on the fluidization of a bed containing fine particles $(d<100 \mu \mathrm{m})$, is the subject of this paper. Practically, it can happen due to breakage or surface abrasion of the fine particles in some processes which totally changes the size distribution and also fluidization behaviour. The materials used in this study are both ground calcium carbonate (GCC); fine is CALCIT MVT 100 (Geldart's group A) and ultra-fine is CALCIT MX 10 (group C). The experimental results for different binary mixtures of these materials (ultra-fines have $30 \%, 50 \%$, or $68 \%$ of the total mixture weight) show that the physical properties of the mixtures are close to those of pure ultra-fine powders. Using mean values of the bed pressure drop calculated from several independent repetitions, the fluidization behaviour of different mixtures are compared and discussed. The fluidization behaviour of the mixtures is non-reproducible and includes cracking, channelling and agglomeration (like for pure ultra-fine powders). Increasing the portion of ultra-fine materials in the mixture causes a delay in starting partial fluidization, an increase in the bed pressure drop as well as a delay in reaching the peak point.
\end{abstract}

Keywords: fine particle; ultra-fine powders; binary mixtures; fluidization; agglomeration; cohesion

\section{Introduction}

Increasing the heat and mass transfer in a fluidization process of particulate materials due to increasing the surface-to-volume ratio is the main reason for the growing use of fluidization in chemical and industrial processes (e.g., granulation, mixing, combustion, coating and chemical reaction processes). Suspended particles have a larger effective surface area (meaning the surface of the particles exposed to the surrounding fluid) than a packed bed. On the other hand, this higher ratio (surface-to-volume) along with the short distance between the small particles leads to strong interactions between them. These interactions affect the flow properties of the particulate material. Based on previous studies [1-5], the fluidization of ultra-fine-and even sometimes of fine-particles is challenging. The cohesive inter-particle forces (van der Waals, electrostatic, liquid bridge forces) are the main reasons for poor fluidization of such powders. Generally speaking, the flow or handling of 
these powders in practical industrial processes is difficult. According to Valverde [6], a gas-fluidized bed of particulate materials can only be stabilized if inter-particle attraction forces have the same order of magnitude as particle weight.

Fine $(d<100 \mu \mathrm{m})$ and ultra-fine $(d<10 \mu \mathrm{m})$ particles have broad applications in many processes (e.g., medicines, paints, catalysts). Nevertheless, the fluidization of these two groups of particles is entirely different. According to Geldart [7], the fluidization of particles by a fluid is classified into four different groups according to the Sauter mean diameter of particles and to the relative density of fluid and particles. Following this classification, CALCIT MVT 100 (fine) and CALCIT MX 10 (ultra-fine) are classified in the easy to fluidize-free flowing-Geldart's Group A and laborious to fluidize-cohesive-Geldart's Group C, respectively.

The fluidization behaviour of particles is affected by both particles and gas properties; that is, density, relative humidity and viscosity of the gas as well as particle parameters such as density, size distribution, surface roughness and hardness, shape, adhesive surface energy and porosity. In addition, the temperature and total pressure of the fluidization column can have significant effects on the fluidization process. Because most of the catalysts used in fluidized bed reactors are classified in the Group A, extensive studies have been dedicated to this group of particles. Previous studies [1,8-10] have shown that the fluidization behaviour of Group A of solid particles in a gas is characterized by easy, particulate or aggregative (bubbling) fluidization with proper mixing, slow deaeration rate and high aeratability. Considering the measured value of minimum fluidization velocity and the calculated Froude number $\mathrm{Fr}=U_{m f}{ }^{2} / g d_{p}$ [11], the fluidization of the fine particles used in this study is classified in the aggregative fluidization behaviour. For fine particles, the adhesion-to-weight ratio (inter-particle forces to hydrodynamics forces) is in the range of 1 to 100, leading to slightly adhesive particles [12]. However, this range of inter-particle forces might be beneficial since they are responsible for an expanded dense phase, which limits the growth of bubbles in the first stage of fluidization [1].

In contrast to this behaviour, for ultra-fine powders, the inter-particle forces are the dominant forces. Practically, for ultra-fine powders that are categorized in the Group C of Geldart's classification, the adhesion-to-weight ratio is in the range of 100 to $10^{4}$, leading to a cohesive or very cohesive material [12]. Therefore, the gas stream cannot easily separate particles; then, cracking or channelling happens, resulting in poor fluidization. Due to the complex behaviour of this kind of powders, the investigations about fluidization of ultra-fine powders have attracted less attention. However, such powders are interesting for a variety of industrial processes, even if their fluidization behaviour is still poorly understood $[1,2,13]$. Corresponding powders are characterized by poor flowability, considerable compressibility and poor permeability.

Experimental results and previous studies indicate that the fluidization of ultra-fine particles usually involves cracking, channelling, plugging (slugging), agglomeration and combinations of those $[2,6]$. Once cracking (horizontal or sloping cracks) happens, the gas phase flows through the resulting narrow openings. Then, when the gas velocity further increases, channelling (vertical channel) occurs and the contact of gas with solid is limited to the channelling zone.

At higher gas velocities, another kind of fluidization may occur. In fact, due to high cohesive forces between particles, some agglomerates are formed with different sizes during fluidization [14,15]; the largest ones are found at the bottom of the bed (some of them are even de-fluidized) and the smallest at the top of it [2]. For improving the fluidization quality of ultra-fine powders, two main methods are available. The first one relies on external forces such as vibrations, either mechanical [16-19], acoustic [20,21], or magnetic [6,22]. Resulting forces help to overcome poor contacting by breaking up the particle agglomerates, destroying most of the formed channels and increasing the bed pressure drop. Therefore, the contact between powders and gas increases and a better suspension of powders arises. The second method involves changing the inherent properties of the particles, either by modifying their surface, like coating the particle surface with nanoparticles [23] or mixing them with other particles that are different in size, density or shape [8,24-26]. The latter method does not need any change in the fluidization column or any extra equipment [8] and is thus particularly attractive. 
When coating with nanoparticles, the van der Waals force, the dominant inter-particle force for dry and neutral powders, decreases dramatically with increasing particle surface distance. When mixing with coarser particles, the resulting bubble motion helps to break the formed agglomerates at the lower half of the fluidization column. According to Ajbar et al. [8], the mixing of particles belonging to different Geldart's classification groups could introduce some interesting behaviour that is not found for single-group fluidization. For example, by adding a small proportion of Group B-particles to a Group D-particle bed, the famous character of coarse particle fluidization (slugging) can be significantly suppressed [27].

Considering the importance of fluidization processes in the industry and the open questions associated to mixed materials fluidization, the goal of this experimental study is to investigate the effect of the presence of different portions of Group C-powders in fine (Group A) particle beds, varying the mass fraction between the fine and ultra-fine materials. Two mixtures with a dominant mass fraction of either fine or ultra-fine particles and a mixture of these two materials in the same weight fraction will be considered. In many industrial processes, parts of the material are fragmented and converted to ultra-fine material due to breakage or surface abrasion of the fine particles as a result of mechanical stresses during particle-particle or particle-wall collisions. This modification of the particle size distribution can change the fluidization of the new mixture. Knowledge about modified fluidization behaviour of a fine particle bed in the presence of ultra-fine powders with the same particle density and origin is important for designing and troubleshooting of these processes.

One example of changes in particle size distribution during a process is the comminution of limestone during batch fluidized bed calcination and sulfation. Here, different comminution processes can occur, "namely primary fragmentation due to release of carbon dioxide during calcination or suddenly heat up of the particles; percolative fragmentation due to loss of connections in the porous structure of the particles; secondary fragmentation yielding relatively coarse non-elutriable fragments; and attrition by surface abrasion due to collisions and surface wear of sorbent particles with bed solids and reactor walls and internals yielding elutriable particles" [28].

In this paper, the process of increasing the gas velocity for fluidizing the particles will be called the loading process. On the other hand, the process of decreasing the gas velocity for a fluidized bed to reach the rest condition will be called the unloading process.

\section{Powder Bed Materials}

In previous publications considered the addition of coarser particles (e.g., [8,24-26]), the added materials were different from the base material, leading in particular to a different density, size and surface properties. In contrast, the present study considers only mixtures of the same material; both particle groups are constituted of ground calcium carbonate with a rhombohedral crystalline structure (according to the technical data sheets of the materials, see Table 1). Calcium Carbonate (also called CALCIT in this article) is a versatile and inexpensive mineral. It has a wide variety of uses in constructional, industrial and environmental applications. Ground calcium carbonate is widely used as the main ingredient of fillers, ceramic tile adhesive and sealants material. Ground Calcium Carbonate (GCC) is a natural source of alkalinity used for de-acidification of rivers, desulphurization of flue gas in power plants and treatment of drinking water. In food industries, GCC is used as a dietary calcium supplement or as a chemical binder. Because of this wide range of application, GCC has been selected as the test material in this study. 
Table 1. Chemical and physical properties of the used materials based on their Technical Data Sheet.

\begin{tabular}{|c|c|c|c|}
\hline \multicolumn{2}{|c|}{ Mineralogical Analysis } & \multirow[t]{2}{*}{$\begin{array}{c}\text { CALCIT } \\
\text { MX } 10\end{array}$} & \multirow[t]{3}{*}{$\begin{array}{c}\text { CALCIT } \\
\text { FW } 270\end{array}$} \\
\hline Origin: & Plant Heidenheim (Germany) & & \\
\hline Characteristics: & Fine crystalline GCC with a rhombohedral crystalline structure. & & \\
\hline \multirow{4}{*}{ Chemical Analysis: } & - $\mathrm{CaCO}_{3}$ & $99.3 \%$ & $98.6 \%$ \\
\hline & - $\mathrm{MgCO}_{3}$ & $0.3 \%$ & $0.5 \%$ \\
\hline & - $\mathrm{Fe}_{2} \mathrm{O}_{3}$ & $0.05 \%$ & $0.1 \%$ \\
\hline & - HCL-insoluble & $0.3 \%$ & $0.7 \%$ \\
\hline \multirow{4}{*}{ Physical Properties: } & - Density (ISO 787/10) & $2.7 \mathrm{~g} / \mathrm{cm}^{3}$ & $2.7 \mathrm{~g} / \mathrm{cm}^{3}$ \\
\hline & - Hardness (Mohs) & 3 & 3 \\
\hline & - $\mathrm{pH}$-value (ISO 787/9) & 9 & 9 \\
\hline & - Refractive index & 1.59 & 1.59 \\
\hline Product & - Particle size distribution (Laser granulometer CILAS 920) & $0-6 \mu \mathrm{m}$ & $0-210 \mu \mathrm{m}$ \\
\hline Characteristics: & - Mean particle diameter $\left(\mathrm{d}_{50}\right)$ (Laser granulometer CILAS 920) & $1.8 \mu \mathrm{m}$ & $70 \mu \mathrm{m}$ \\
\hline
\end{tabular}

The fine (Group A) material called CALCIT MVT 100 was prepared by classification of CALCIT FW 270 with a water-jet sieving method followed by a drying process, as described in Reference [29]. The ultra-fine (Group C) material is CALCIT MX 10. Both raw materials (CALCIT FW 270 and CALCIT MX 10) were supplied by Sh minerals GmbH Company and had the same origin (Heidenheim Plant, Heidenheim, Germany).

Figure 1 shows the cumulative size distribution functions of these materials. The measurement of particle size distribution is done by a laser diffraction method (Malvern Mastersizer 2000). The principle of this method is based on measuring the angular variation in the intensity of light scattered as a laser beam passes through a dispersed particle. Large particles scatter light at small angles and small particles scatter light at large angles relative to the laser beam. In both wet and dry methods, it is important to distinguish the agglomerates from dispersed particles. In the present work, a dry measurement is used. By controlling the pressure drop to induce shear processes, all agglomerates are disintegrated into primary particles. To reduce attrition, high flow rates of air are used. To check reproducibility, all measurements have been repeated several times.

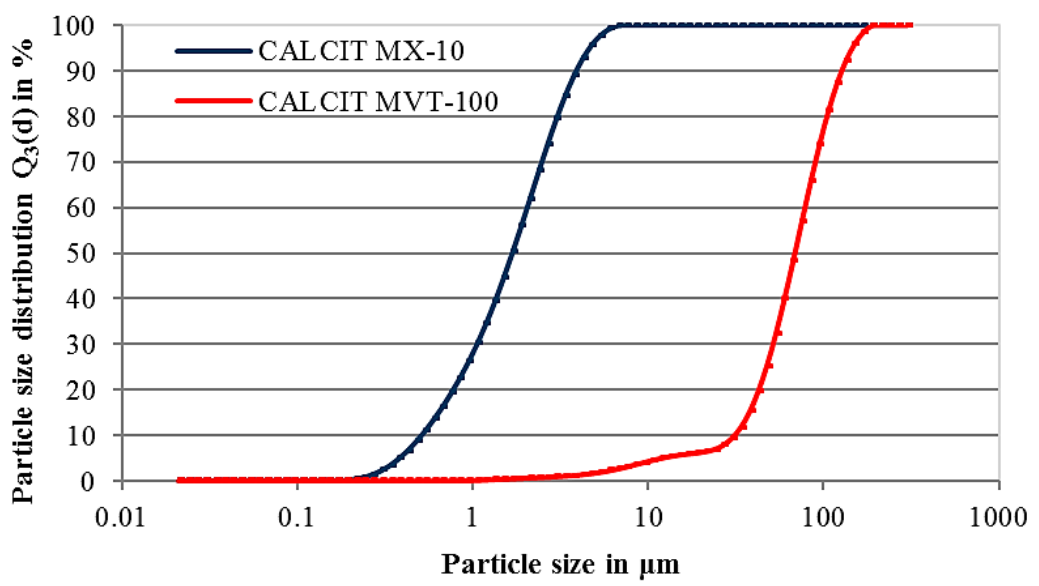

Figure 1. Cumulative size distribution functions of both used materials (laser Mastersizer 2000).

The properties of the particles used in this study are summarized in Table 2. This table compares the mass-mean particle diameter $\left(d_{50}\right)$, Sauter mean diameter $\left(d_{\mathrm{ST}}\right)$, bulk density $\left(\rho_{b}\right)$, particle density $\left(\rho_{p}\right)$, the intensity of cohesiveness $(c)$ and also flow function $\left(f f_{c}\right)$ of these two materials. The two latter properties of the materials, as well as bulk density, have been extracted from experimental results using a ring shear cell (Dr. Dietmar Schulze-RST-XS.S) shown in Figure 2a. According to the shear test theory for the yield locus line (the yield locus represents the shear stress that is required to initiate flow 
(failure) as a function of normal stress), the intensity of cohesiveness is related to the shear stress $(\tau)$ and normal stress $(\sigma)$ by

$$
\tau=\sigma \tan \varphi_{i}+c
$$

where $\varphi_{i}$ is the angle of internal friction. For clarification, Figure $2 \mathrm{~b}$ shows a general graph describing the Yield Locus line.

Table 2. Properties of powders used in this study.

\begin{tabular}{ccccccc}
\hline Particulate Material & $d_{\mathbf{5 0}} \times \mathbf{1 0}^{\mathbf{6}}(\mathbf{m})$ & $d_{S T} \times \mathbf{1 0}^{\mathbf{6}} \mathbf{( m )}$ & $\rho_{\boldsymbol{b}}\left(\mathbf{k g} / \mathbf{m}^{\mathbf{3}}\right)$ & $\rho_{p}\left(\mathbf{k g} / \mathbf{m}^{\mathbf{3}}\right)$ & $c\left(\mathbf{N} / \mathbf{m}^{\mathbf{2}}\right)$ & $f f_{c}$ \\
\hline CALCIT MVT 100 & 73 & 38 & 1241 & 2700 & 84 & 11 \\
CALCIT MX 10 & 1.8 & 1.23 & 756 & 2700 & 915 & 1.33 \\
\hline
\end{tabular}

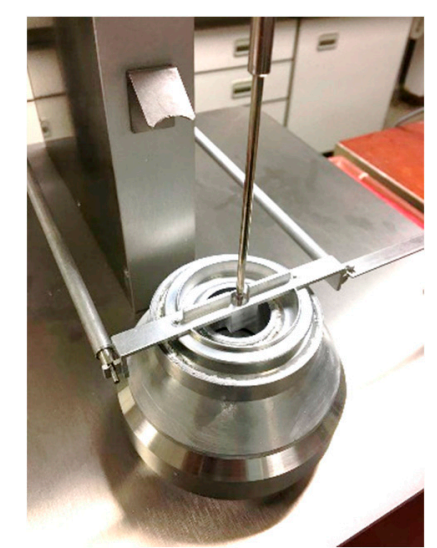

(a)

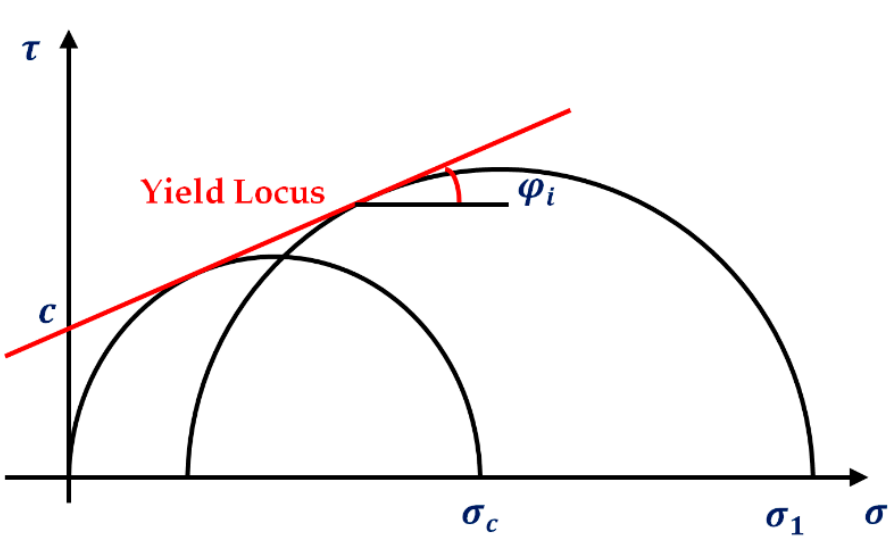

(b)

Figure 2. (a) Ring shear cell, (b) Yield locus line.

The second parameter, the flow function of the bulk solid is calculated as the ratio between its consolidation stress, $\sigma_{1}$ and the unconfined yield strength, $\sigma_{c}$, in a determined storage period, $t$. It is written as $f f_{c}=\sigma_{1} / \sigma_{c}$. A smaller $f f_{c}$ represents a worse bulk solid flowability. According to Table 2, the fine material is a free-flowing material $\left(f f_{c}>10\right)$, while the ultra-fine material is classified as a very cohesive material $\left(1<f f_{c}<2\right)$ [30].

Given that the fluidization process occurs in a fixed-geometry column (same cross-section area), to have the same conditions for comparing the results of all experimental tests, the total weight of materials (pure or mixed) in all particle beds used in this study is the same. Since all of the material in the different experiments have the same weight, comparing directly the bed pressure drop to investigate fluidization behaviour is reasonable. Also, since both base materials have the same origin, the particle densities of both fine and ultra-fine materials are the same (Table 2).

According to Rabinovich and Kalman [31], the classification of fluidization could be characterized not only by Geldart's classification method but also with the Archimedes number (Ar):

$$
\operatorname{Ar}=\frac{g \cdot d_{p}^{3}\left(\rho_{p}-\rho_{g}\right)}{\vartheta_{g}^{2} \cdot \rho_{g}}
$$

where $g$ is the gravity acceleration, $\vartheta_{g}$ is the kinematic viscosity of the gas, $d_{p}$ is the particle diameter and finally $\rho_{g}$ is the gas density. By substituting the required parameters at Standard Ambient Temperature and Pressure (SATP) condition (298.15 K and $100 \mathrm{kPa}$ ) for air in Equation (2), Archimedes number for fine and ultra-fine materials are 5.315 and 0.00018 , respectively. Again, the fine material can be classified in Group A $(1<\mathrm{Ar}<80)$, while the ultra-fine material belongs to Group C, which is very cohesive [32]. 


\section{Experimental Apparatus and Methodology}

Figure 3a shows the test rig designed for this study. The principal component of the experimental test rig is a transparent glass column with $760 \mathrm{~mm}$ height, $100 \mathrm{~mm}$ inner diameter and $10 \mathrm{~mm}$ wall thickness. To ensure a uniform gas distribution in the fluidization process, an aluminium gas distributor plate with staggered rows $\left(60^{\circ}\right)$ arrangement of numerous identical holes with a diameter of $1.5 \mathrm{~mm}$ and a pitch of $2.35 \mathrm{~mm}$ is placed at the bottom of the column. This perforated plate is covered with a set of two Sartorius FT-3-202-125 Filter Papers-Grade 289 to prevent particles from passing through the distribution plate during unloading. Dried compressed air at ambient temperature is used as the fluidizing gas and its flow rate is controlled by a calibrated Burkert flow controller. The humidity and temperature of air are measured during all fluidization tests with a Testo- 480 device to ensure negligible changes concerning moisture content.

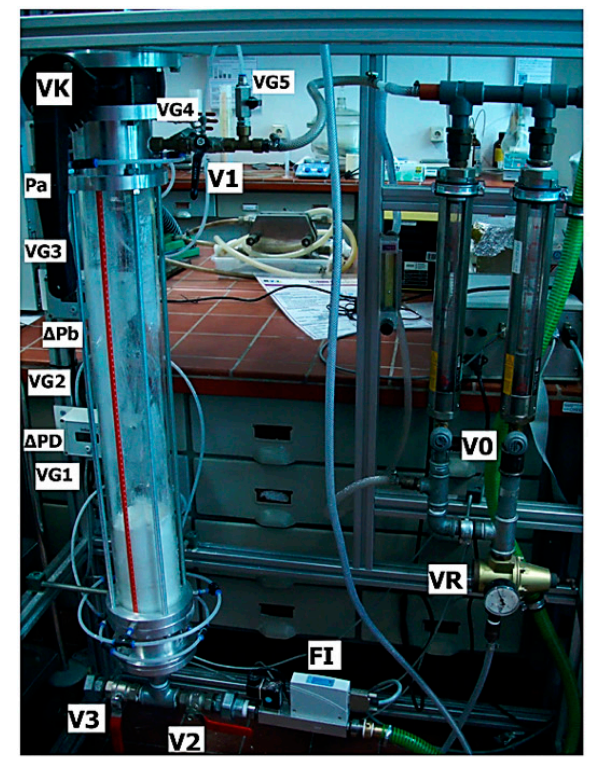

(a)
V: Ball valve to control air direction VG: Ball valve to control pressure transmitters VR: Regulating valve

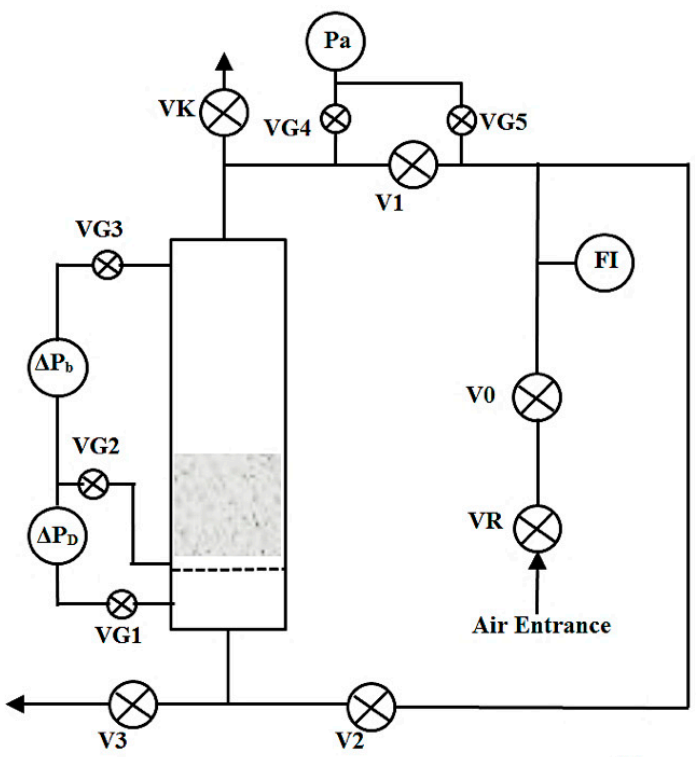

VK: Butterfly valve FI: Flow controller

Figure 3. (a) Snapshot and (b) scheme of the test rig.

Three Kalinsky pressure transmitters are used to monitor the pressure drop of the gas distributor $\left(\Delta P_{D}\right)$, the bed pressure drop $\left(\Delta P_{b}\right)$ and the gauge pressure within the apparatus $\left(\mathrm{P}_{\mathrm{a}}\right)$. They operate in the range of 0-2000 mbar. The height of the bed (h) is measured by the ultrasonic method, based on sending an ultrasonic wave and measuring the reflection time. In this study, the bed height in each measurement is obtained by averaging the measured heights at eight different locations. Figure $3 \mathrm{~b}$ shows the scheme of the experimental apparatus. For the fluidization tests, the dried air (fluidizing gas) comes from the bottom of the column to the system and after passing through the powder bed goes out of the column from the VK valve (see Figure 3b).

An exhaust air filter at the top of the test rig is used to prevent elutriation loss. Before transferring the particulate materials to the fluidization column, an anti-static spray is used to limit the effect of electric charges on the column wall. In this study, the focus is set on fluidization behaviour around minimum fluidization velocity $\left(U_{m f}\right)$; higher velocities that may lead to elutriation of particles from the fluidization domain are ignored. Minimum fluidization velocity is the smallest superficial gas velocity at which fluidization occurs [33]. The particle size distribution and the weight of the remaining material in the fluidization column are measured after each fluidization test. In this manner, it can be ensured that the elutriation of ultra-fine particles is negligible. 
Each mixture is prepared carefully using an Eirich mixer (EL01). Then, four samples are prepared from four different positions of the mixed material and the particle size distribution is checked to ensure the homogeneity of the mixture. Some segregation and compaction could happen during the transfer of materials to the column. This effect is small, due to the gradual transfer and to the low height from the free surface of the bed and new charged material. In this manner, similar conditions are obtained for all tests, reducing possible history effects as much as possible.

\section{Experimental Results and Discussion}

\subsection{Determination of the Range of Superficial Gas Velocity}

The fluidization starts when the pressure drop across the bed is equal to the weight of the bed divided by its cross-section area $\left(P_{w b}\right)$. Before fluidization, in the fixed primary condition, the bed pressure drop $\left(\Delta P_{b}\right)$ linearly increases when increasing the superficial gas velocity $\left(U_{s g}\right)$. According to theory [11], when $\Delta P_{b}$ approaches $P_{w b}$, it begins to saturate, that is, there is no change in $\Delta P_{b}$ when increasing gas velocity. However, when inter-particle adhesive forces are dominant, actual practices [11] show that the pressure drop balances $P_{w b}$ at a theoretical level of $U_{m f}$, but that inter-particle forces prevent the particle bed from fluidization albeit the gas velocity is increased above $U_{m f}$. Then, there is a peak in the bed pressure drop, which is observed due to the extra pressure required to overcome these forces. This behaviour can also happen due to a pre-compaction of the bed, or due to wall effects for a small bed diameter.

The $U_{m f}$ is defined as the intersection point of linearly extrapolating the fixed bed line (in $\Delta P_{b}$ vs. $U_{s g}$ curve) and the fully fluidized state line. By considering the well-known Ergun equation [34] for the pressure drop of a gas stream across a packed bed and assuming negligible cohesive force between particles, the pressure drop at $U_{m f}$ should be equal to the weight per cross section area of the particle bed. By substituting this equation and after some simplifications, Wen and $\mathrm{Yu}$ [35] indicated that the Reynolds number at minimum fluidization condition $\left(\operatorname{Re}_{m f}\right)$ is given for a wide range of particle Reynolds numbers $(0.001<\operatorname{Re}<4000)$ as:

$$
\operatorname{Re}_{m f}=\sqrt{33.7^{2}+0.0408 \mathrm{Ar}}-33.7
$$

Then, $U_{m f}$ can easily be given by

$$
U_{m f}=\frac{R e_{m f} \cdot \vartheta_{g}}{d_{p}}
$$

Grace [36] proposes 27.2 instead of 33.7 suggested by Wen and Yu (Equation (3)) to improve the results for fine particles. His equation is then

$$
\operatorname{Re}_{m f}=\sqrt{27.2^{2}+0.0408 \mathrm{Ar}}-27.2
$$

Another helpful empirical equation for calculating $U_{m f}$ was proposed by Leva [37] as

$$
U_{m f}=\frac{7.169 \times 10^{-4}\left(\rho_{p}-\rho_{g}\right)^{0.94} d_{p}^{1.82} g}{\rho_{g}^{0.06} \mu_{g}^{0.88}}, \operatorname{Re}_{m f}<30
$$

where $\mu_{g}$ is the dynamic gas viscosity. Note that all these equations were obtained based on experimental observations for particles with $d_{p}>20 \mu \mathrm{m}$.

For smaller particles, by considering the van der Waals cohesive force between particles, $\mathrm{Xu}$ and Zhu [38] offered a new equation for Group C-particles as

$$
\operatorname{Re}_{m f}^{2}+\frac{85.71\left(1-\varepsilon_{m f}\right)}{\varphi_{s}} \operatorname{Re}_{m f}=E_{G}+E_{c}
$$


where $\varepsilon_{m f}$ is the void fraction in minimum fluidization condition and $\varphi_{s}$ is particle sphericity. In addition, $E_{G}$ and $E_{c}$ represent the gravitational and cohesive effects, respectively. Considering mechanical vibration as a fluidization aid, they offered the following equation for estimating $\varepsilon_{m f}$ as

$$
\varepsilon_{m f}=0.77\left(d_{p} \times 10^{6}\right)^{-0.124}
$$

In addition, $E_{G}$ and $E_{\mathcal{c}}$ can be calculated as

$$
\begin{gathered}
E_{G}=0.57 \varphi_{s} \cdot \varepsilon_{m f}^{3} \cdot \operatorname{Ar} \\
E_{\mathcal{C}}=4.79 \times 10^{-9} \frac{\varphi_{s} \cdot \varepsilon_{m f}^{0.52} \cdot \rho_{g} \cdot d_{p}}{L_{0} \cdot \mu_{g}^{2}}
\end{gathered}
$$

where $L_{0}$ is the settled bed height (initial bed height). When the initial bed height is not measured, it can be estimated by

$$
L_{0}=\frac{m_{s}}{A\left(1-\varepsilon_{m f}\right) \rho_{p}}
$$

where $A$ is the bed cross section area and $m_{s}$ is the total mass of the particle bed.

Using Equations (3), (5) and (6) for fine particles, the minimum fluidization velocities are calculated as $0.128,0.159$ and $0.157 \mathrm{~cm} / \mathrm{s}$, respectively. Using Equation (7), $U_{m f}$ is predicted as $0.01185 \mathrm{~cm} / \mathrm{s}$ for ultra-fine particles. However, since the $\varepsilon_{m f}$ in Equation (10) is obtained by considering mechanical vibration - a feature that is not used in the present study, the value of $U_{m f}$ calculated with Equation (7) is expected to be much smaller than the real $U_{m f}$ for a bed consisting of ultra-fine powders without any fluidization aid.

It should be noted here that any meaningful quantification of $U_{m f}$ is practically impossible for ultra-fine cohesive powders (as already clear from previous studies [1,2]). In fact, due to the formation, destruction and re-formation of cracks and channels, measurements of the bed pressure drop for ultra-fine cohesive powders are non-reproducible, showing highly unsteady features. The bed structure of this kind of material can become suddenly disrupted at some characteristic velocity. After disruption, a superficial gas velocity that matches the maximum bed pressure drop is observed. Hereafter, the corresponding velocity is called after-disruption velocity, $U_{a d}$. The point where the process reaches the after-disruption condition is also called the peak point, since it corresponds with the maximum of $\Delta P_{b}$. In Reference [2], the use of this velocity $U_{a d}$ instead of $U_{m f}$ is suggested for comparison between different fluidization processes.

When increasing the superficial gas velocity, it is expected that the smaller particles start to elutriate before the coarse particles. At the same time, at higher superficial gas velocity, it is expected that notable aggregation occurs between ultra-fine cohesive powders. The ratio of the effective size of these agglomerates to the size of the single particles increases with decreasing size of the single particles. The density and the effective mean size of the formed clusters (agglomerates) are such that $U_{m f}$ for the mixture will be far higher than $U_{m f}$ for a single particle class. This explains why a bed of ultra-fine particles remains unfluidized at gas velocities that are several times the $U_{m f}$ corresponding to mean diameter of the individual particle. Turki and Fatah [39] reported that, for nanoparticles, this can be up to $3 \times 10^{6}$ times the gas velocity for fluidizing the single particles. The measurements of the portion of elutriated particles from the bed in this study show that the range of the minimum fluidization velocity ratio for ultra-fine (micron size) powders is not so large.

The measured superficial gas velocities for starting partial fluidization combined with the measurement of particle size distribution and weight of material remaining in the column after fluidization, show that the loss of particles due to elutriation and their exit from the fluidization column is negligible even up to about 1200 times the calculated $U_{m f}$ of single particles. This is due to the formation of agglomerates at higher velocities and dominant cohesive forces. Nevertheless, by 
increasing superficial gas velocity to achieve ultra-fine fluidization, the elutriation losses generally increase. Considering all these issues together, the velocity range for all fluidizations lies between $0-15 \mathrm{~cm} / \mathrm{s}$. The superficial gas velocity is increased from zero to the maximum velocity in 35 equal steps for all the fluidization loading processes and is decreased in 18 steps for all unloading processes.

\subsection{Fluidization of Fine and Ultra-Fine Particles Separately}

The experimental tests start with the results of fluidization tests for fine and ultra-fine particles separately, before investigating the effect of the presence of some specified percentage of ultra-fine powders on fluidization of a fine-particle bed. Figures 4 and 5 show the fluidization curve, that is, the variation of bed pressure drop $\left(\Delta P_{b}\right)$ when increasing superficial gas velocity $\left(U_{s g}\right)$, for two independent fluidization tests for CALCIT MVT 100 (fine material) and CALCIT MX 10 (ultra-fine material), respectively. For each superficial gas velocity, ample time (up to $5 \mathrm{~min}$ ) is considered to ensure that the bed pressure drops have reached stable values before recording is started. In fact, for fine particles, steady-state conditions are really obtained. However, for ultra-fine powder, the fluctuations in the bed pressure drop can remain relatively high. Here, the pressure drops presented in this work are the mean value, averaged over the last minute of the recording for each superficial gas velocity (it means, if the ample time is $5 \mathrm{~min}$ for each record, the averaging has been done during the fifth minute, not for whole five minutes).

\subsubsection{Fine Particle Bed Fluidization}

a. Loading: The fine (Group A) particles fluidization at $U_{m f}$ shows an almost homogeneous non-bubbling fluidization followed by bubbling fluidization as gas velocity increases. Before $U_{m f}$, in the fixed bed state, the pressure drop increases linearly when increasing the superficial gas velocity. According to Ergun's equation [34], the gas pressure drop during the passage of a fluid through a porous medium (fixed bed) is calculated as

$$
\frac{\Delta P_{b}}{L_{0}}=150 \frac{\mu_{g} U_{s g}(1-\varepsilon)^{2}}{d_{p}^{2} \varepsilon^{3}}+1.75 \frac{\rho_{f} U_{s g}^{2}(1-\varepsilon)}{d_{p} \varepsilon^{3}}
$$

In the fixed bed zone, the superficial gas velocities are very low. Therefore, the first term on the right side of the Ergun Equation (viscous term), which corresponds to the Blake-Kozeny equation for laminar flow is much larger than the second term (kinetic term), which corresponds to the Burke-Plummer equation for turbulent flow. Consequently, the variation of bed pressure drop with gas velocity is almost linear.

The fluidization curve smoothly saturates at the fully fluidized state (Figure 4). This is because the fine material used in this study has a wide particle size distribution (PSD), from $1 \mu \mathrm{m}$ to about $200 \mu \mathrm{m}$ (Figure 1). Wide size distribution of particles has different effects on the fluidization behaviour, such as smaller void sizes [40], a greater air retention capacity [41], enhanced fluidity, increased segregation and partial mixing [42]. A wide PSD also reduces the bubble size in bubbling fluidization mode [43]. Fluidization starts as an increase in bed height. The expansion of the bed before starting bubble formation is a result of the nucleation of micro-cavities in the bed. The size range of these cavities is between one and ten particle diameters. For this condition (bubble-free), by increasing the gas velocity, the number of cavities does not change, but their size starts to increase [3]. The cohesive force between particles fixes the cavities' walls and disconnection of weakly-bonded particles is the reason for developing cavity growth. After that, when increasing gas velocity, bubbling occurs. It should be recalled here that Archimedes number for the used fine material is about 5.315 and the bed height to diameter ratio is $L_{0} / D_{b}<1$. Thus, when increasing gas velocity, only bubbling happens and there is no slugging behaviour [32]. However, the dissipation of energy during the bubbling condition is very low and it does not lead to important changes in the bed pressure drop. Therefore, after starting fluidization, the pressure drop is almost constant. 
b. Unloading: Figure 4 also shows that the fluidization loading and unloading curves follow one another closely; only a slight hysteresis effect is evident. In fact, for this kind of material, weak cohesive forces between particles result in decreasing extra-energy for overcoming such forces in fluidization loading. Small hysteresis effects in this material are due to collisions between particles, some irreversible deformations [44] and limited segregation effects [45].

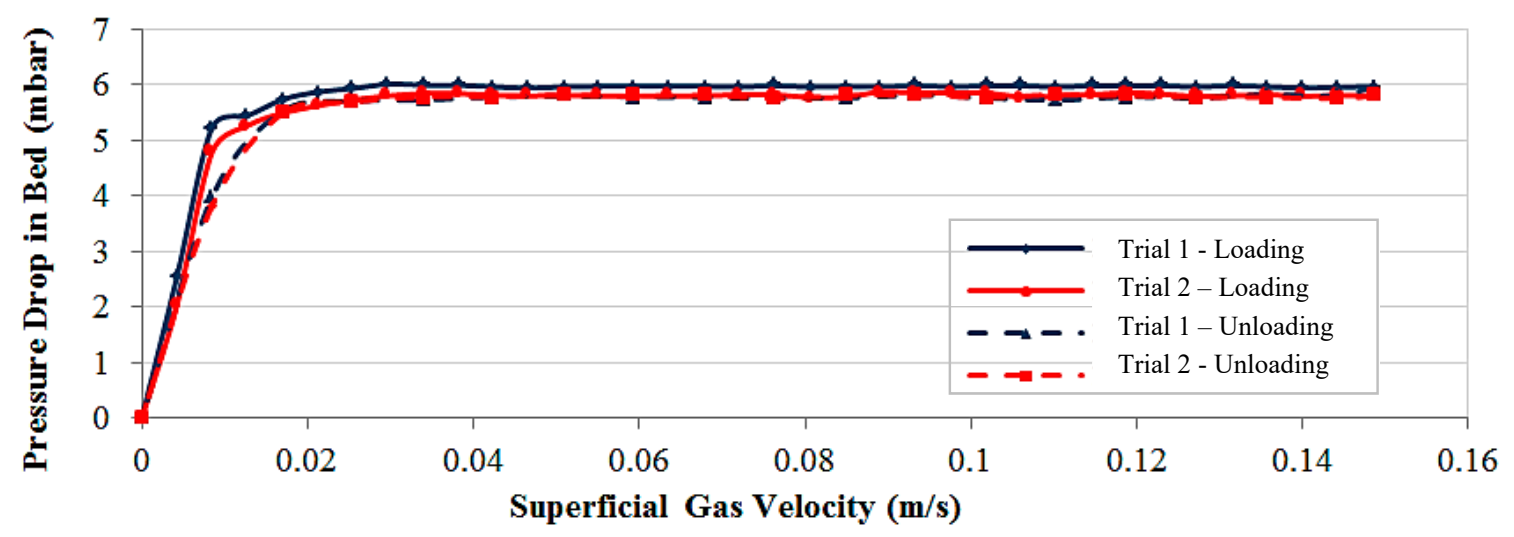

Figure 4. Two independent fluidization tests-Loading (-) and Unloading (- - ) of fine powder bed (CALCIT MVT-100).

\subsubsection{Ultra-Fine Powder Bed Fluidization}

a. Loading: For fluidization of ultra-fine cohesive powder, it is clear from Figure 5, that there are strong fluctuations in the bed pressure drop when looking at the loading curves. This figure shows two independent fluidization tests for the same ultra-fine powder. For a fixed bed condition, by increasing the gas velocity, the pressure drop also increases. However, there is not any change in the bed height. Again, a linear trend is observed between the rising bed pressure drops and increasing gas velocity. Focusing on the first trial fluidization curve (dark blue), the general behaviour of the loading curve of ultra-fine cohesive powders can be discussed qualitatively. As a complementary source of information, Figure 6 also shows pictures corresponding to three different behaviours of ultra-fine particle fluidization during the first fluidization test as shown in Figure 5.

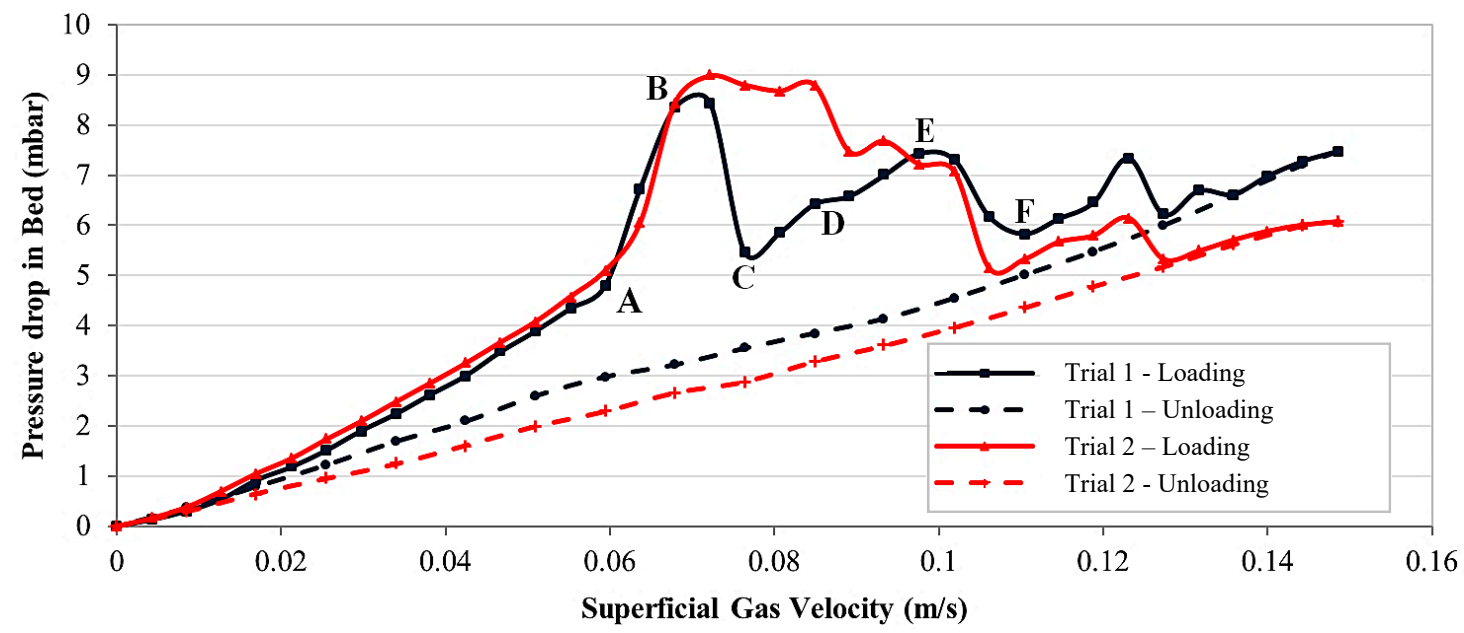

Figure 5. Two independent fluidization tests_Loading (-) and Unloading (- - ) of ultra-fine powder bed (CALCIT MX-10). 
(B-C)

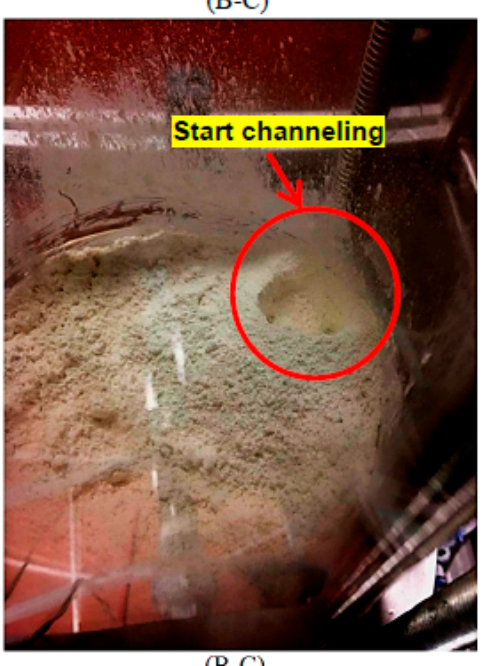

(B-C)

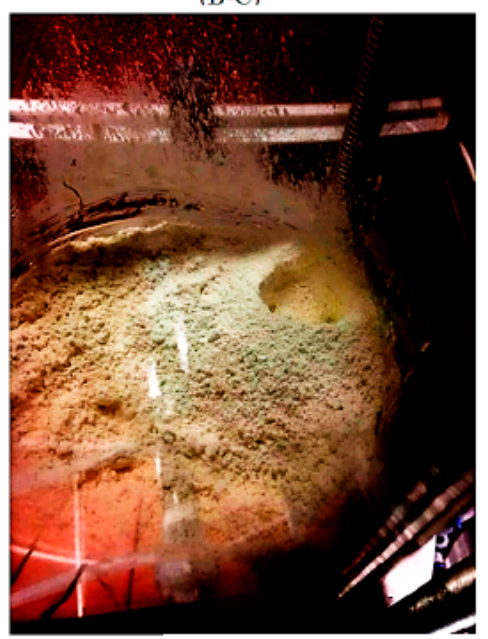

(C-D-E)

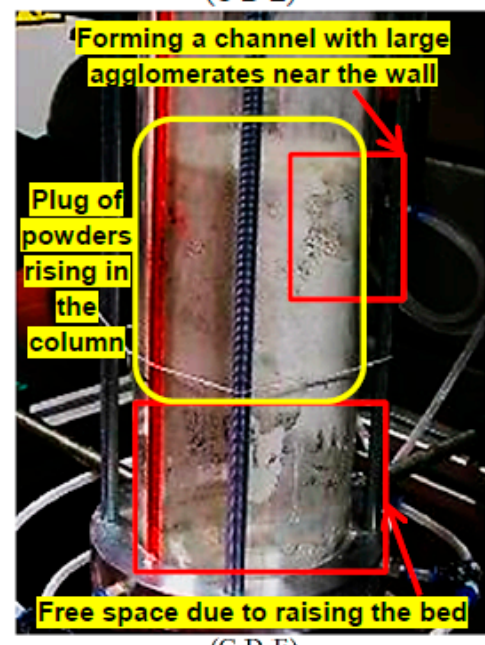

(C-D-E)

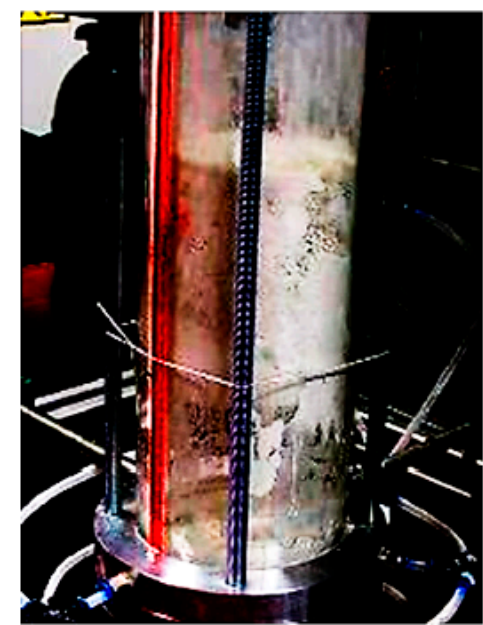

(E-F)

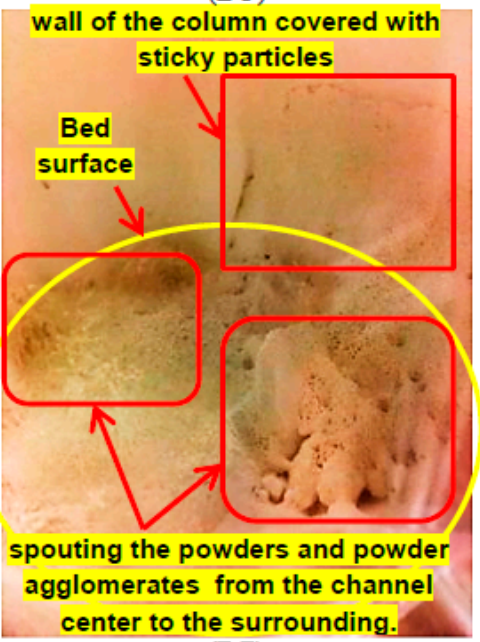

(E-F)

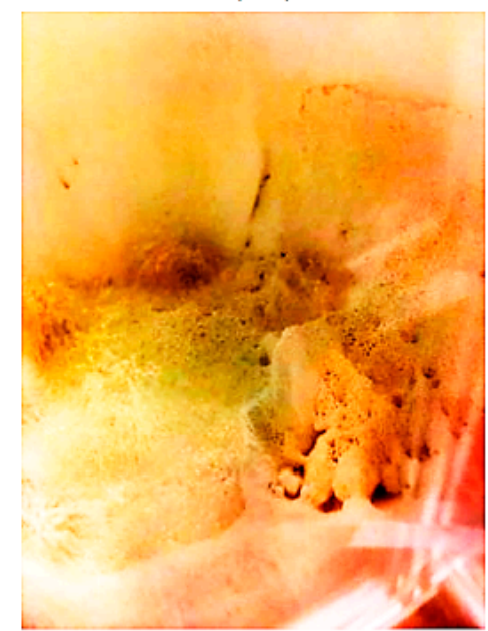

Figure 6. Three different behaviours of ultra-fine particle fluidization during the first test shown in Figure 5: First row: (B-C) start channelling and decrease of bed pressure drop; (C-D-E) rising of the upper part of the bed as a plug in the fluidization columns, accompanied by a competition between formation and destruction of some small channels in the raised bed; (E-F) top view of bed surface showing the wall of the column covered with sticky particles and some large channels after collapse of the raised bed, spouting the powders and powder agglomerates from the channel centre to the surrounding-Second row: High-contrast pictures for better observations.

By increasing the gas velocity, some horizontal or sloping cracks first begin to form. At point A, the formed cracks have been broken down and, due to this phenomenon, the slope of the changes in the bed pressure drop increases when increasing the superficial gas velocity. This behaviour continues up to point B. At this point, at which enough kinetic energy becomes available in the gas, the available voids between cohesive powders and their adjacent cracks connect and build vertical channels. This leads to a finite expansion of the bed, but without formation of a real bubble. Then, some small bubbles (unlike the bubbling behaviour seen in fluidization of Group A-particles) form.

Due to the motions of these small bubbles, the cracks formed near the wall disappear. The moving bubbles re-shape the cracks until they take the form of vertical channels. After starting of channelling, the pressure drop decreases suddenly to point $C$. In fact, because of channels, the gas stream now has a shortcut to pass the powder bed and needs a lower pressure drop to cross the porous medium.

Increasing the superficial gas velocity further, the available gas in the cracks and adjoining voids escapes the bed and the cracks break and fall down. The ratio at which the available gas in micro-voids 
can leave a vertical channel will control the rate of collapse [1]. After the channels collapse, the pressure drop again increases. The collapsed bed forms a network of adhered powders and a large horizontal crack is formed near the bottom of the bed. When further increasing the gas velocity, due to retention of air under the upper part of the powder bed, this upper part starts to rise in the column as a slug flow, as long as the flow rate of the air entering into this gap is higher than the flow of air passing through the upper part of the powder bed. The formation of some small channels in the upraised part of the bed after point $\mathrm{D}$ is the reason of increasing pressure drop with a different slope (lower) up to point E. Increasing further the gas velocity, a large channel is activated, causing the collapse of the raised part of the bed at point F. Finally, the fluidization continues in the channelling regime.

This first trial fluidization curve (the dark blue one) reveals all essential features of fluidization for Geldart's Group C-powders. However, as revealed by a second independent test (red curve), not all features will be systematically observed. For the second fluidization test, the fluctuations in the pressure drop are due to activation and collapse of cracks or channels, but the rising bed, as seen in the previous test between points $C$ and E, was not observed. Figure 6 shows three photos taken during the first test and illustrating the key features of ultra-fine fluidization at macro-scale.

Figure 6 shows that there are a lot of random phenomena during fluidization of ultra-fine particles, such as formation and disruption of cracks and channels, agglomeration, slug flow, spouting behaviour of channels, the sticking of powder to the column walls, movements of active channels and of fluidized and de-fluidized zones when increasing or decreasing the superficial gas velocity. All these features are a direct function of the exact initial conditions of the bed before starting fluidization; though the bed properties are statistically identical for all tests, the exact local distribution of the particles at initial time varies from realization to realization and also depends on the previous state of the bed (the condition of the bed for each level of gas velocity) during fluidization loading and unloading (history effect). Therefore, the behaviour of ultra-fine fluidization is different for each independent test even when using the same material, as shown in Figure 5.

b. Unloading: The unloading curves of ultra-fine powder fluidization show a substantially different (almost linear) behaviour compared to the loading curves (Figure 5). The pressure drop measurements during unloading lie entirely below the loading. Based on Darcy's law, the total volumetric flow rate of the fluid passing through a porous medium formed by particles, $\dot{V}$, can be represented using the height and cross-section area of the powder bed as:

$$
\dot{V}=k \cdot A \cdot H G, \quad H G=\Delta h_{w} / \Delta h_{b}
$$

where $H G$ is the hydraulic gradient, $\Delta h_{w}(\mathrm{~m})$ is the pressure drop across the bed, $\Delta h_{b}(\mathrm{~m})$ is the height of the bed, A is the total cross-sectional area of the bed and $k$ is a constant depending on the physical properties of the particle bed and fluid (permeability). Then, the mean velocity of the fluid $\left(U_{s g}\right)$ is defined as:

$$
\dot{V} / A=U_{s g}=k \cdot \Delta h_{w} / \Delta h_{b} \Longrightarrow k \propto U_{s g} / \Delta h_{w} \text { and } \Delta P_{b}=\rho_{f} g \Delta h_{w}
$$

where $\Delta P_{b}$ is the bed pressure drop.

Considering that the slope of the $\Delta P_{b}-U_{s g}$ graph is inversely proportional to permeability, $k$ (refer to Equation (14)), the linear behaviour of the unloading curve shows a constant permeability in the powder bed during unloading. It means that for ultra-fine material, although permeability of the bed during loading changes several times due to competing phenomena taking place at this stage (as discussed before), the unloading process is much simpler and permeability is almost constant (Figure 5).

On the other side, the permeability of the fine particle bed increases in the loading process with almost the same rate as it decreases during the unloading process, as mentioned in connection with Figure 4.

It is worth noting that for the ultra-fine material, observations never show a fully fluidized bed; a partially-fluidized bed is systematically seen, involving cracking, channelling, plugging (slugging), 
collapsing and agglomeration of the powders. Similar observations are also reported by Wang et al. [2]. This shows that the fluidization behaviour of the ultra-fine material is not stable and is very sensitive to the initial conditions and history of the bed before starting (initial arrangement of particles) and during fluidization tests. Therefore, a considerable effort has been spent to ensure identical initial conditions (in a statistical sense) for all fluidization tests.

\subsubsection{Using Agglomeration Number to Evaluate the Fluidization Behaviour of Cohesive Particles}

One criterion for describing the fluidization behaviour of cohesive powders involves the interaction of formed agglomerates with peripheral adhered powders. When the size of particles is reduced down to the micrometre range, particles try to build agglomerates to reduce their surface energy. Zhou and Li [24] defined the particle agglomeration number (Ae) as a criterion that indicates whether particles fluidize or not:

$$
\mathrm{Ae}=F / \operatorname{Re}=\frac{c \cdot \mu_{g}}{U_{s g} \cdot \rho_{g} \cdot \rho_{a g} \cdot d_{p}^{2} \cdot g}
$$

where $F$ comes from the ratio of $F_{c} / F_{g} . F_{c}$ is the cohesive force between agglomerates and their peripheral adhered powders and $F_{g}$ is the gravity of the peripheral adhered spherical powders. In addition, Zhou and Li [24] estimated the agglomerates density $\left(\rho_{a g}\right)$ as 1.15 times that of the packed bed density; they concluded that the cohesive particles can be fully fluidized if Ae $\leq 40,000$. Using the particle properties in this study, Ae is much larger than 40,000 for the ultra-fine material in the range of gas velocities considered here $(0-15 \mathrm{~cm} / \mathrm{s})$.

The critical value of 40,000 would be obtained for a huge gas velocity of $2700 \mathrm{~cm} / \mathrm{s}$, at which all particles (agglomerates) would be pneumatically transported out of the fluidization column. Thus, increasing the gas velocity to such a high value is impossible. The fact that the criterion of Zhou and $\mathrm{Li}$ [24] is not valid here shows that the ultra-fine material is a very cohesive powder and it has not full fluidization. Therefore, if the fluidization of such ultra-fine materials is necessary for an industrial process, some kind of fluidization aids, as discussed in the introduction section, is required to reduce the agglomeration number.

For our fine particles, Ae is smaller than 40,000, even at low gas velocities, explaining easy and full fluidization of fine particles in the experiments.

\subsection{Fluidization of Binary Mixtures, as a Combination of Fine and Ultra-Fine Particles}

The first point of investigating the binary mixtures is to find the suitable weight percentages of ultra-fine materials in the mixtures. For this purpose, a series of initial tests were carried out with increasing the proportion of ultra-fine particles in the mixtures by $5 \%$ in each step and checking the fluidization behaviour. These experiments showed that increasing the portion of ultra-fine particles to more than $20 \%$ by mass results in partial fluidization (cracking, channelling or slug flow). For all blends containing more than $20 \%$ of ultra-fine particles, the mixture could not be fluidized completely. For a mixture with $20 \%$ of ultra-fine powders, the full fluidization happens first at high gas velocities, leading to elutriation loss. Below $20 \%$ of ultra-fines, the behaviour of the mixture changes due to the presence of ultra-fine material. However, reaching fluidization is still possible by increasing the gas velocity; a higher percentage of ultra-fine powders requires a higher superficial gas velocity for fluidization.

These observations can also be explained by looking again at the particle agglomeration number, Ae. For a mixture of two material (binary mixture), Ae can be calculated by [24]:

$$
\mathrm{Ae}=\frac{c_{M} \cdot \mu_{g}}{U_{s g} \cdot \rho_{f} \cdot \rho_{a g} \cdot d_{s t, M}^{2} \cdot g}
$$


where $c_{M}$ is the intensity of cohesiveness for the binary mixture (as measured in the shear cell for each mixture) and $d_{s t, M}$ is the Sauter mean value of particle diameters in the mixture, which is given by

$$
1 / d_{s t, M}=\sum_{j=1}^{2} w_{j} / d_{p_{j}}
$$

where $d_{p_{j}}$ is the mean particle size and $w_{j}$ is the weight fraction of the sample particle $j$ in the mixture.

The values of Ae according to Equation (16) reveal that a mixture containing $20 \%$ of ultra-fines is expected to be fluidized for superficial gas velocities higher than $39.5 \mathrm{~cm} / \mathrm{s}$ (i.e., this gas velocity corresponds to Ae $<40,000$ [24]).

Therefore, in this study, only portions (mass-weighted ratio) of ultra-fine particles above the critical value (20\%) are considered in what follows. Finally, three percentages of ultra-fine powders (30\%, $50 \%$ and $68 \%$ of the total weight of the mixture) in the mixtures will be employed. Following [24], for the lowest percentage of ultra-fine powders (30\%), the velocity where Ae $<40,000$ would be $115 \mathrm{~cm} / \mathrm{s}$, which is already much larger than the acceptable velocity for avoiding elutriation loss.

Table 3 shows the properties of all mixtures used in the experiments. The values of $\rho_{b}, c_{M}$ and $f f_{c}$ are measured by the same shear cell test device used for the measurements in Table 2. The parameter $d_{M}$ is calculated according to Equation (17). Considering the relative density of solid and gas as well as the value of $d_{M}$, all mixtures belong to the very cohesive Geldart's Group C. However, increasing the ultra-fines in the mixture decreases flowability and increases the intensity of cohesiveness. For a higher percentage of ultra-fines, saturation is observed: $c_{M}$ for compositions containing $50 \%$ and $68 \%$ of ultra-fine particles is only $6 \%$ and $2 \%$ smaller than pure ultra-fine powder, respectively. Figure 7 shows the increase of $c_{M}$ when increasing the ultra-fine powders in the binary mixtures. This graph includes pure fine and ultra-fine particles as two mixtures containing $0 \%$ and $100 \%$ of ultra-fine powder, respectively.

Table 3. Properties of the powder mixtures used in this study.

\begin{tabular}{cccccc}
\hline $\begin{array}{c}\text { Powder Combination } \\
\text { (\% Fine-\% Ultra-Fine) }\end{array}$ & $d_{s t, \boldsymbol{M}} \times \mathbf{1 0}^{\mathbf{6}} \mathbf{( \mathbf { m } )}$ & $\boldsymbol{\rho}_{\boldsymbol{b}} \mathbf{( \mathbf { k g } / \mathbf { m } ^ { \mathbf { 3 } } )}$ & $\boldsymbol{\rho}_{\boldsymbol{p}} \mathbf{( \mathbf { k g } / \mathbf { m } ^ { \mathbf { 3 } } )}$ & $\boldsymbol{c}_{\boldsymbol{M}} \mathbf{( \mathbf { N } / \mathbf { m } ^ { \mathbf { 2 } } )}$ & $f_{\boldsymbol{c}}$ \\
\hline $70-30$ & 5.67 & 1149 & 2700 & 572 & 1.9 \\
$50-50$ & 3.51 & 1053 & 2700 & 862 & 1.40 \\
$32-68$ & 2.62 & 926 & 2700 & 903 & 1.35 \\
\hline
\end{tabular}

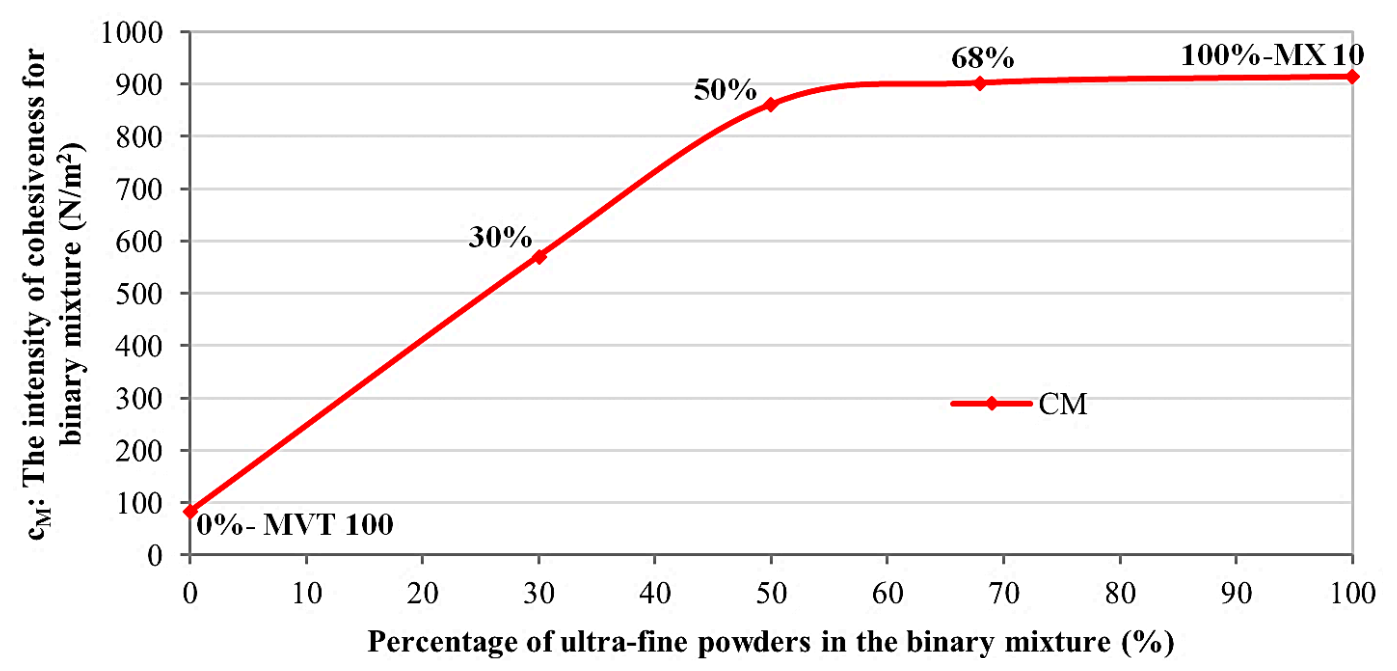

Figure 7. Change in the intensity of cohesiveness for a binary mixture when increasing the percentage of ultra-fine powders. 
In addition, Figure 8 shows the cumulative distribution function and probability density function of the particle size for a binary mixture of $50 \%$ ultra-fine and $50 \%$ fine particles, illustrating the typical distribution of particle size in such binary mixtures.

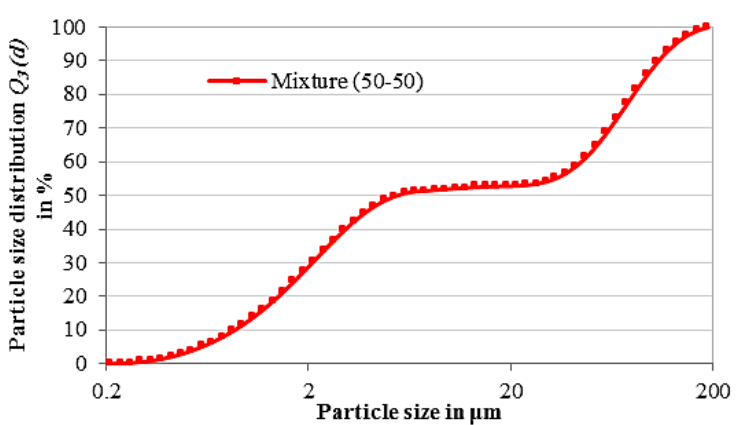

(a)

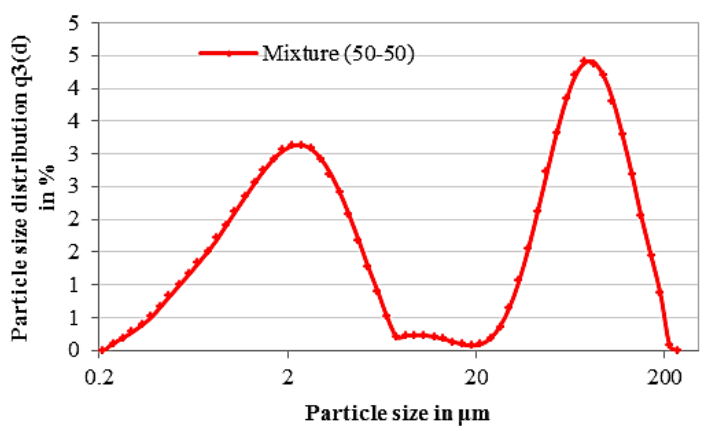

(b)

Figure 8. (a) Cumulative distribution function (b) Probability density function of the particle size for a binary mixture of $50 \%$ of ultra-fine $+50 \%$ of fine particles (laser Mastersizer 2000).

Figures 9-11 show two independent repetitions of the fluidization tests $\left(\Delta P_{b}-U_{s g}\right.$ graphs) for the three different mixtures of fine and ultra-fine particles, with weight percentage combination (fine $\%$-ultra-fine $\%$ ) of $70 \%-30 \%, 50 \%-50 \%$ and $32 \%-68 \%$, respectively.

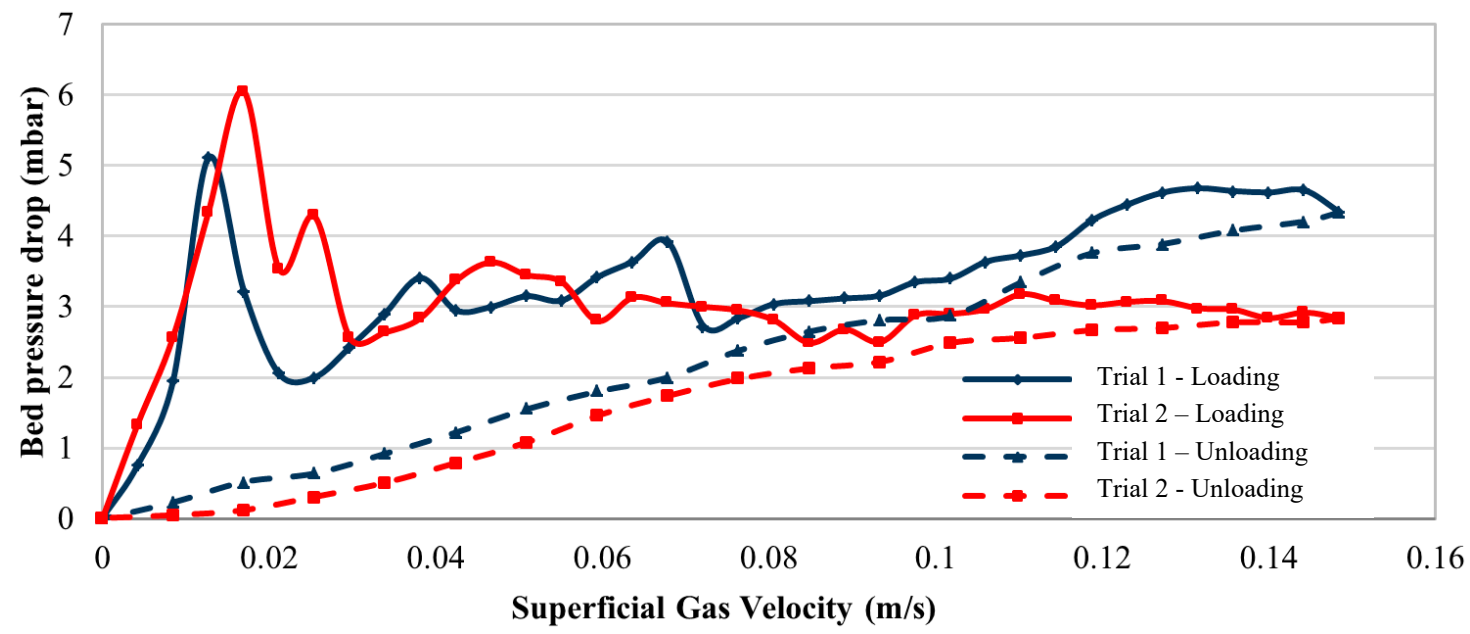

Figure 9. Two independent fluidization tests-loading (-) and unloading (- - ) of mixed material- $(30 \%$ of ultra-fine $+70 \%$ of fine particles $)$.

These figures show that the fluidization curves of loading and unloading are qualitatively similar to the fluidization curve for ultra-fine cohesive powders discussed previously; strong fluctuations in bed pressure drop are observed during loading, with an almost linear behaviour during the unloading stage. These figures show that the presence of ultra-fine cohesive powders can change entirely the fluidization behaviour of the fine particle bed. It is again clear that the fluidization tests for all these mixtures are not reproducible. Changes between two different repetitions of fluidization tests with the same material (as observed in Figures 9-11) are due to differences in the initial conditions, to the past history of the particles regarding applied forces and to the stochastic formation and collapsing of cracks and channels. These factors will change the fluidization curve in each test repetition (history-dependent). 


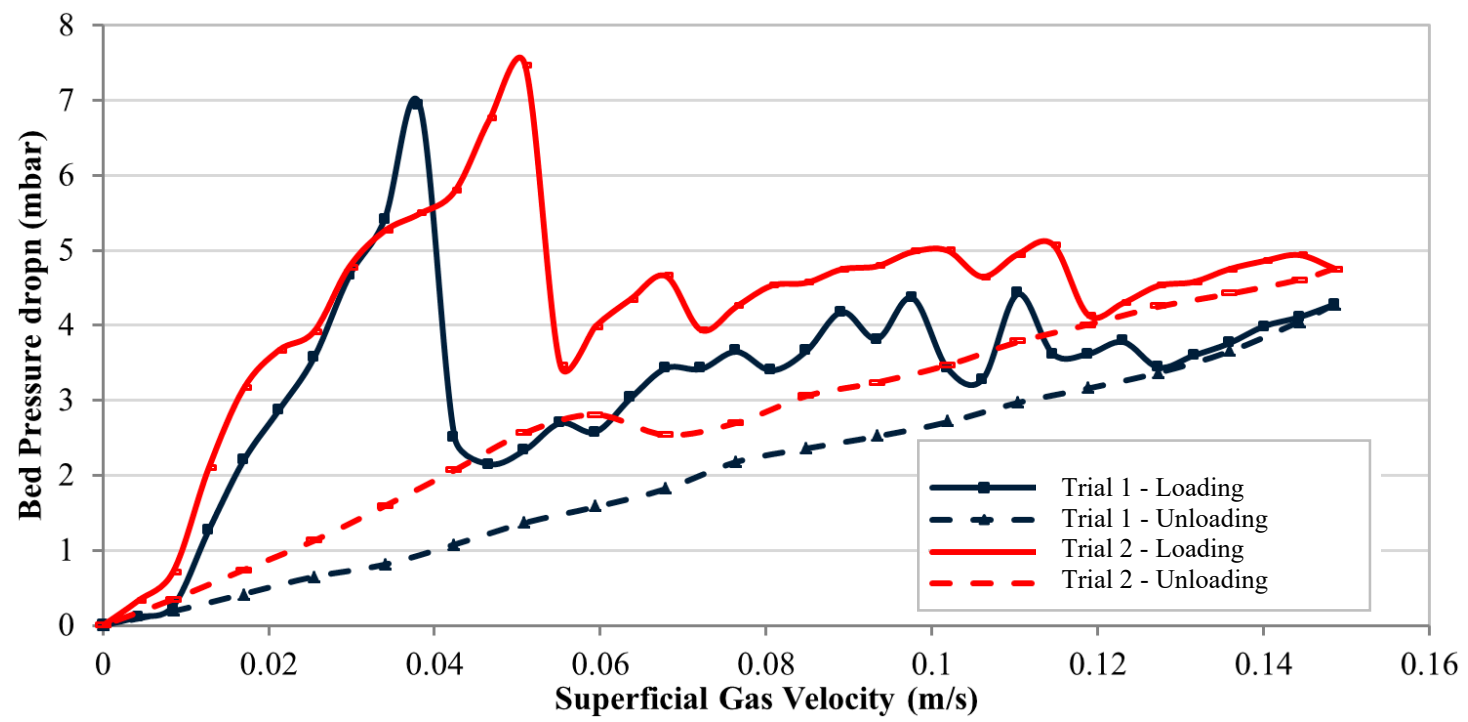

Figure 10. Two independent fluidization tests-loading (-) and unloading (- -) of mixed material- $(50 \%$ of ultra-fine $+50 \%$ of fine particles $)$.

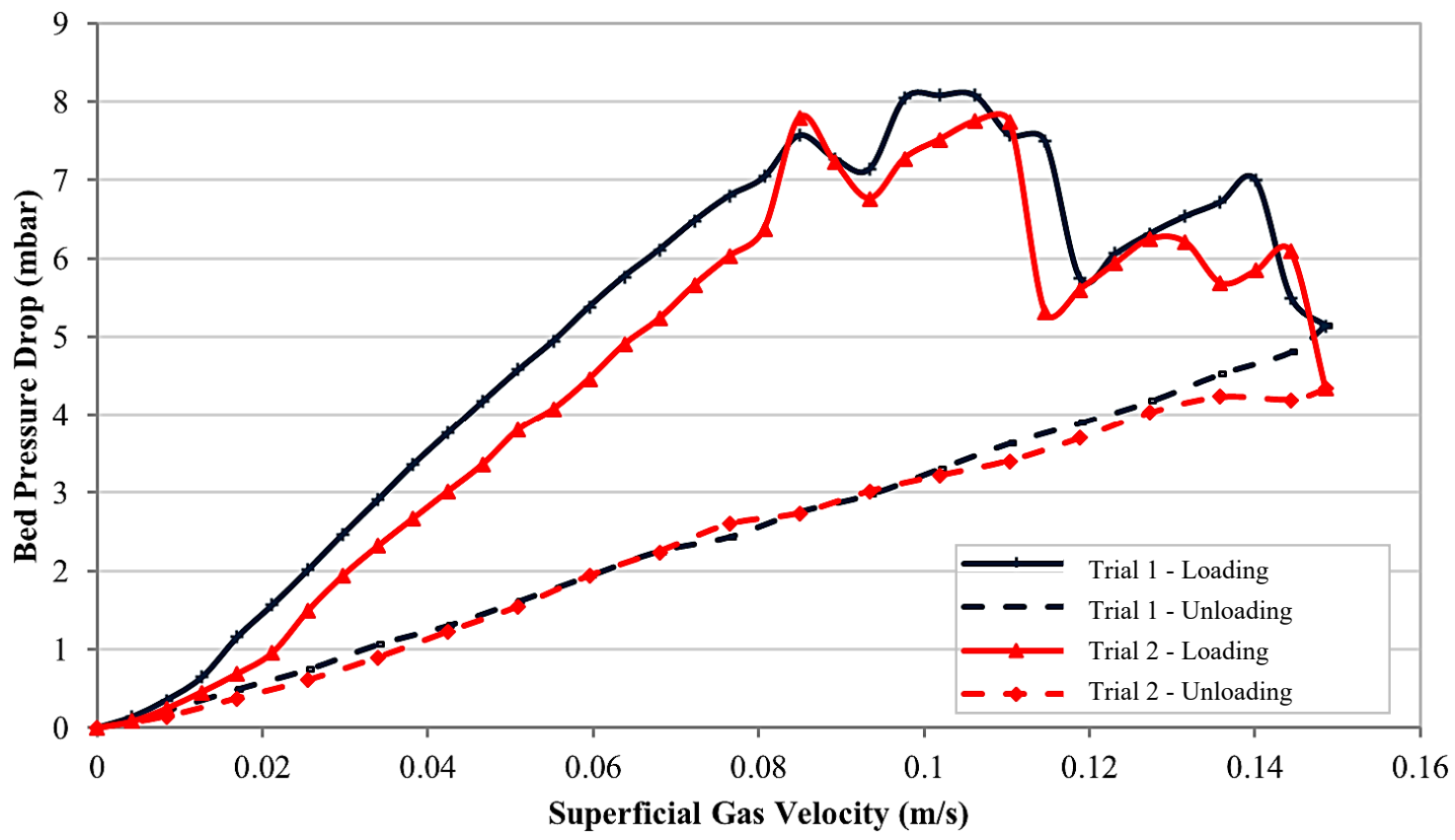

Figure 11. Two independent fluidization tests-loading $(-)$ and unloading $(--)$ of mixed material- $(68 \%$ of ultra-fine $+32 \%$ of fine particles $)$.

4.4. Using the Mean Value of Bed Pressure Drop as a Criterion for Comparing Non-Reproducible Fluidization Processes

In this study, several independent fluidization tests were performed for the three combinations of fine and ultra-fine particles. Considering that each test takes about eight working hours (including discharging the previous material, cleaning, preparation, charging the new material, loading to fluidization and unloading), the number of tests for each mixture was restricted by time: ten tests have been carried out for each combination of materials. Given that $\Delta P_{b}\left(U_{s g}\right)$ is different for each repetition of the measurements, the mean value of bed pressure drop at each superficial gas velocity for all repetitions of the same process will be used for the further discussion.

For a better understanding of the averaging process, Figures 12 and 13 show the mean values (symbols) and the standard deviations (indicated graphically by vertical error bars, although they are 
not errors) of the measured bed pressure drop of fine and ultra-fine materials for each gas velocity and for all repetitions, respectively. It is clear, that the fluidization of fine particles (Figure 12) is stable, with a negligible effect of initial conditions; the only noticeable variation appears at the fluidization point but is still very small. On the other hand, although all experiments correspond to the same initial conditions in a statistical sense, as discussed previously, for ultra-fine powders (Figure 13), very large variations in the bed pressure drop are observed for most superficial gas velocities.

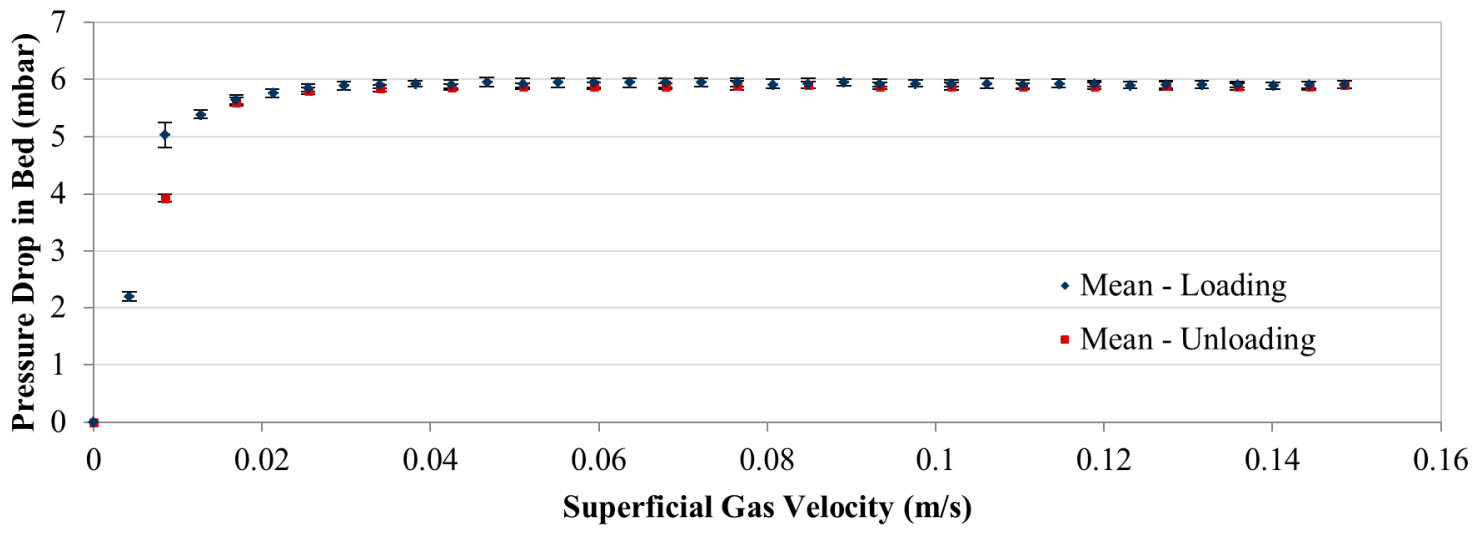

Figure 12. Mean value (symbols) and standard deviation (vertical bars) of $\Delta P_{b}\left(U_{s g}\right)$ when repeating fluidization tests for fluidization loading and unloading of fine particle bed (CALCIT MVT-100).

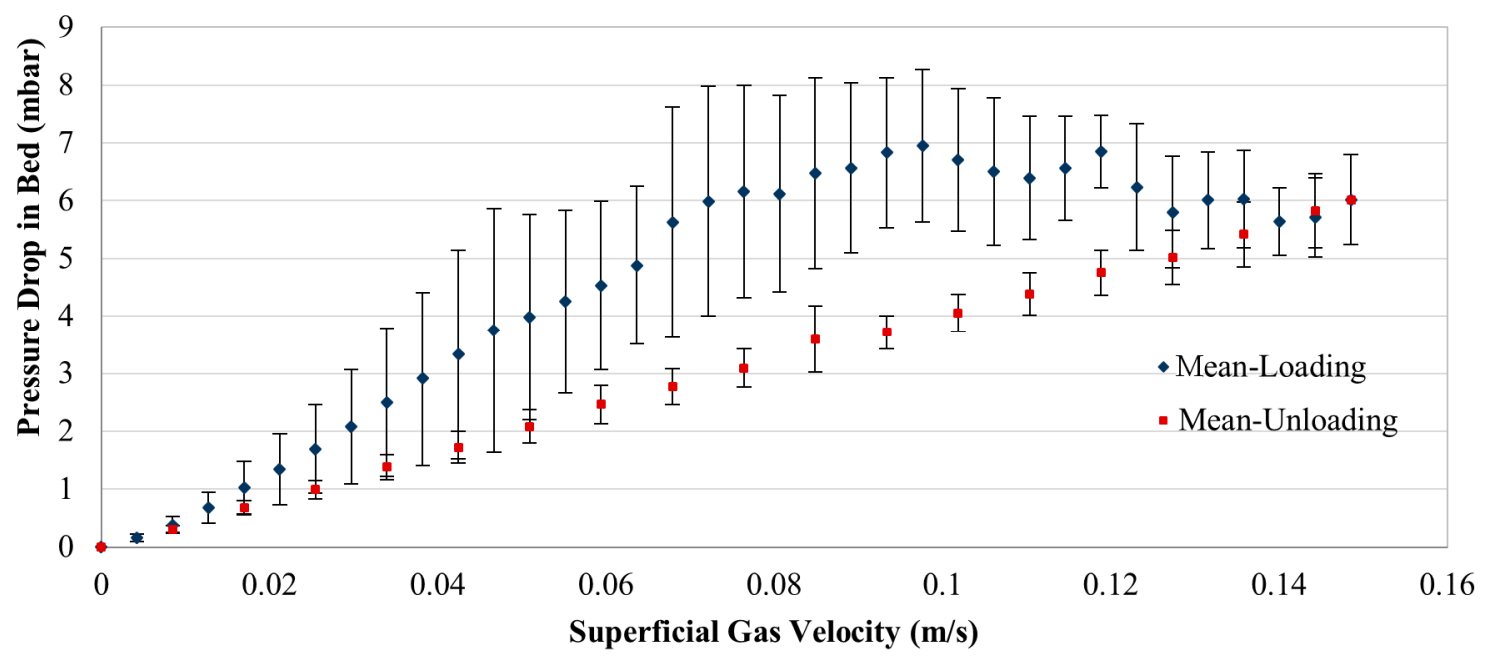

Figure 13. Mean value (symbols) and standard deviation (vertical bars) of $\Delta P_{b}\left(U_{s g}\right)$ when repeating fluidization tests for fluidization loading and unloading of ultra-fine powder bed (CALCIT MX-10).

Using the mean value of $\Delta P_{b}$, it becomes possible to check and compare the overall fluidization behaviour for each mixture. For this reason, for each superficial gas velocity, only the mean value of the bed pressure drops calculated from the experimental results of all repetitions will be presented and discussed in what follows.

Again, the investigation starts with the mean value of the experimental results for the fluidization of fine and ultra-fine cohesive materials (Figures 14 and 15), separately.

In the case of fine particles (Figure 14), the process is stable, as discussed previously. Only negligible fluctuations are observed concerning $\Delta P_{b}$ and the system shows a fully fluidized bed behaviour.

On the other hand, the results of Figure 15 show that the fluidization of ultra-fine particles is not a fully fluidized behaviour and that considerable pressure drop fluctuations occur during the loading stage. According to the previous definition, the superficial gas velocity corresponding to the 
peak point is called the after-disruption velocity $\left(U_{a d}\right)$. Figure 15 indicates that for ultra-fine material, $U_{a d}=9.76 \mathrm{~cm} / \mathrm{s}$ and the peak of bed pressure drop is 7.11 mbar. An accurate definition of $U_{m f}$ is impossible here, since the fluidization tests are not reproducible. However, using the mean value curve, a pseudo- $U_{m f}$ can be extracted from Figure 15, based on the intersection of the extrapolated line of fixed bed condition and the mean-value line of the fluctuations of the bed pressure drop in the partial fluidization condition. This method leads to a pseudo- $U_{m f}$ of $8.19 \mathrm{~cm} / \mathrm{s}$ for this case.

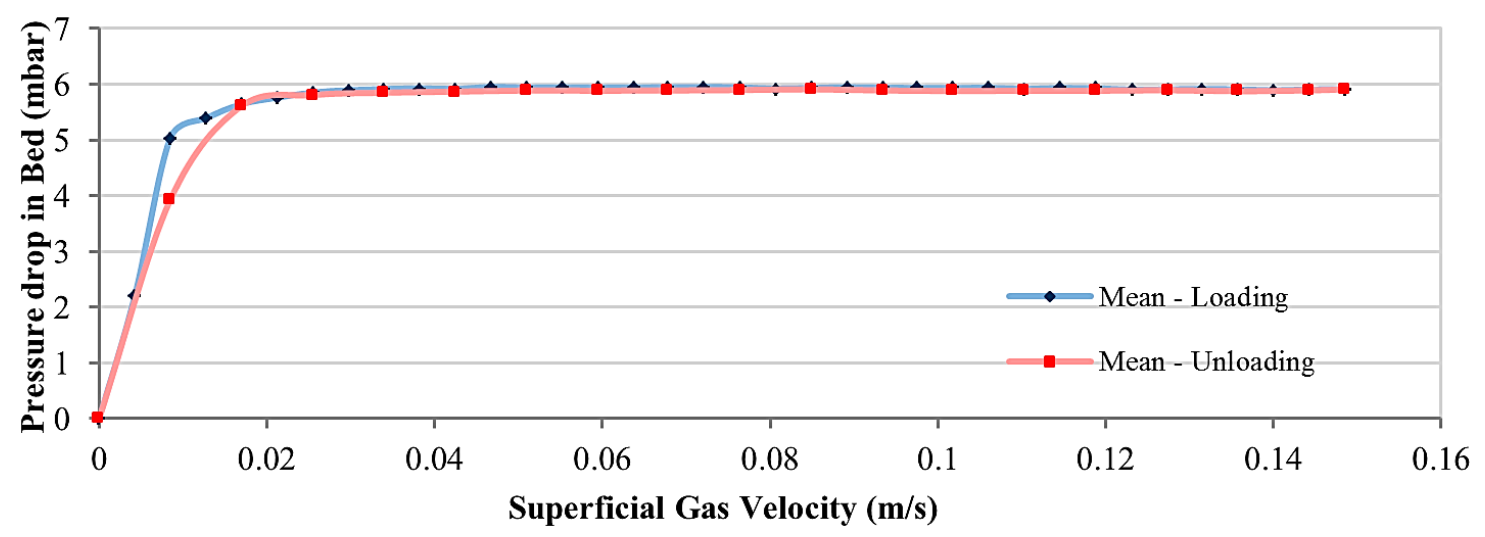

Figure 14. Mean value of $\Delta P_{b}\left(U_{s g}\right)$ when repeating fluidization tests for fluidization loading and unloading of fine particle bed (CALCIT MVT-100).

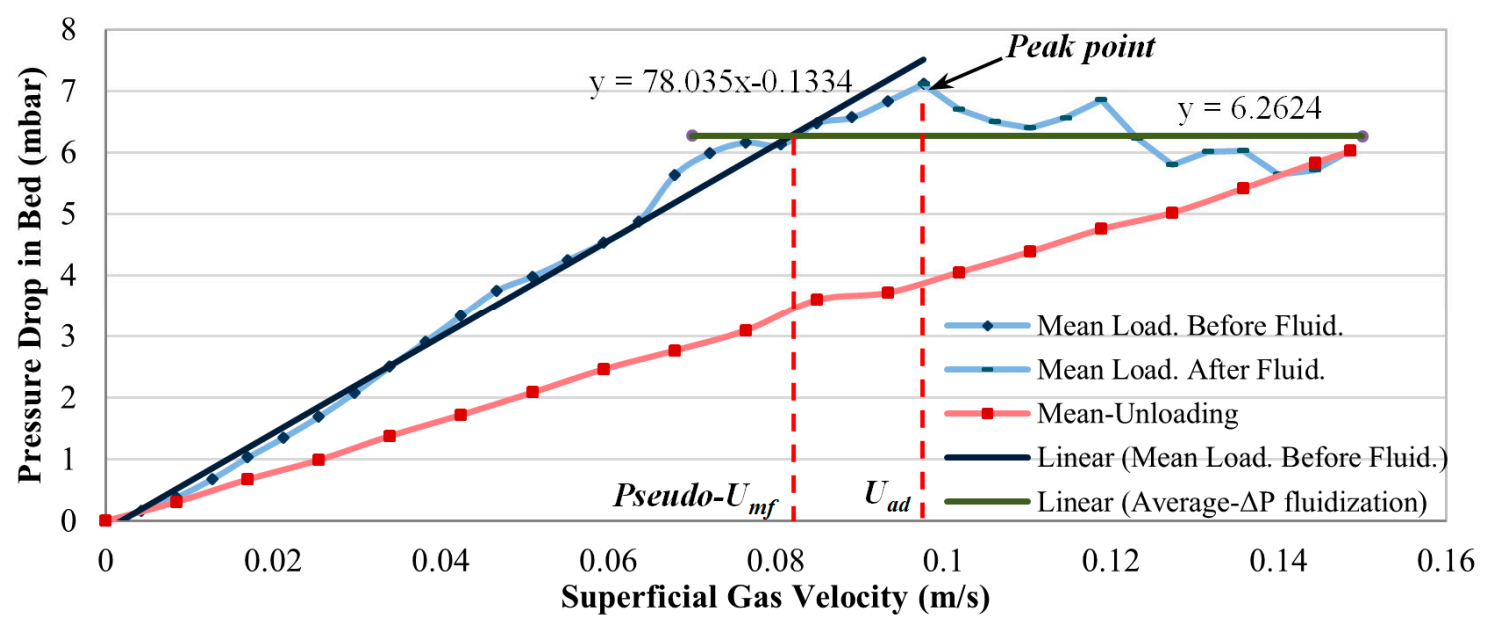

Figure 15. Mean value of $\left(\Delta P_{b}\left(U_{s g}\right)\right.$ when repeating fluidization tests for fluidization loading and unloading of ultra-fine powder bed (CALCIT MX-10).

The previous conditions correspond to the two extremum conditions of only fine or only ultra-fine particles. For different combinations of the primary materials, Figures 16-18 depict the behaviour of the mean bed pressure drop averaged over all realizations.

The figures also show the peak point (corresponding to the maximum of $\Delta P_{b}$ ), the after-disruption velocity $U_{a d}$ related to this point and the fitting lines used for estimating pseudo- $U_{m f}$ velocities. Comparing the average curves in the loading stage, it appears that by increasing the ultra-fine material in the mixture, the peak value of $\Delta P_{b}$ increases $(4.407,5.04$ and $7.05 \mathrm{mbar}$ for $30 \%, 50 \%$ and $68 \%$ of the ultra-fine material in the total weight of the mixtures, respectively). The superficial gas velocities corresponding to these peak points $\left(U_{a d}\right)$ also increase when increasing the percentage of ultra-fine powders in the mixture (they are $5.5,6.79$ and $8.49 \mathrm{~cm} / \mathrm{s}$, respectively). In addition, the results show that by increasing the percentage of ultra-fine powder in the mixtures, the obtained pseudo- $U_{m f}$ velocities also increased $(2.6,4.06$ and $7.32 \mathrm{~cm} / \mathrm{s}$ for $30 \%, 50 \%$ and $68 \%$ of ultra-fine material in the mixtures, respectively). Generally speaking, increasing the percentage of ultra-fine materials in the 
mixture causes a delay in the onset of partial fluidization (it appears first at higher superficial gas velocities), an increase in the bed pressure drop, as well as a delay in reaching the peak point.

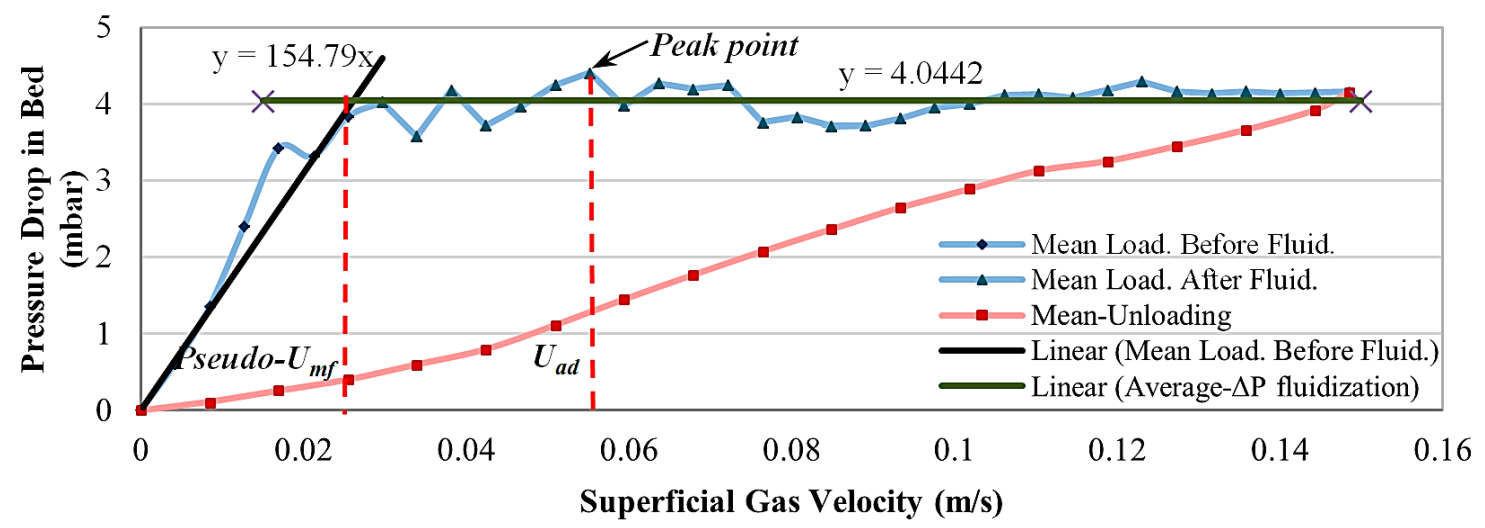

Figure 16. Mean value of $\Delta P_{b}\left(U_{s g}\right)$ when repeating fluidization tests for fluidization loading and unloading of mixed material-( $30 \%$ of ultra-fine $+70 \%$ of fine particles).

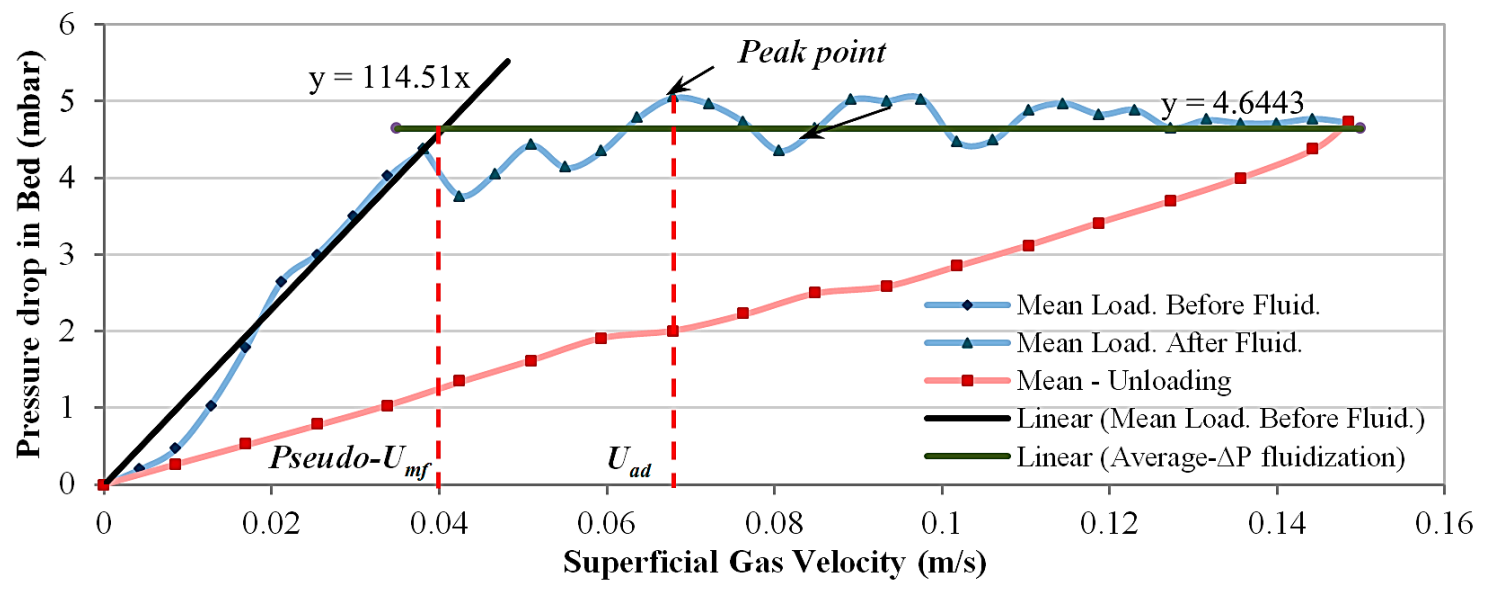

Figure 17. Mean value of $\Delta P_{b}\left(U_{s g}\right)$ when repeating fluidization tests for fluidization loading and unloading of mixed material-( $50 \%$ of ultra-fine $+50 \%$ of fine particles).

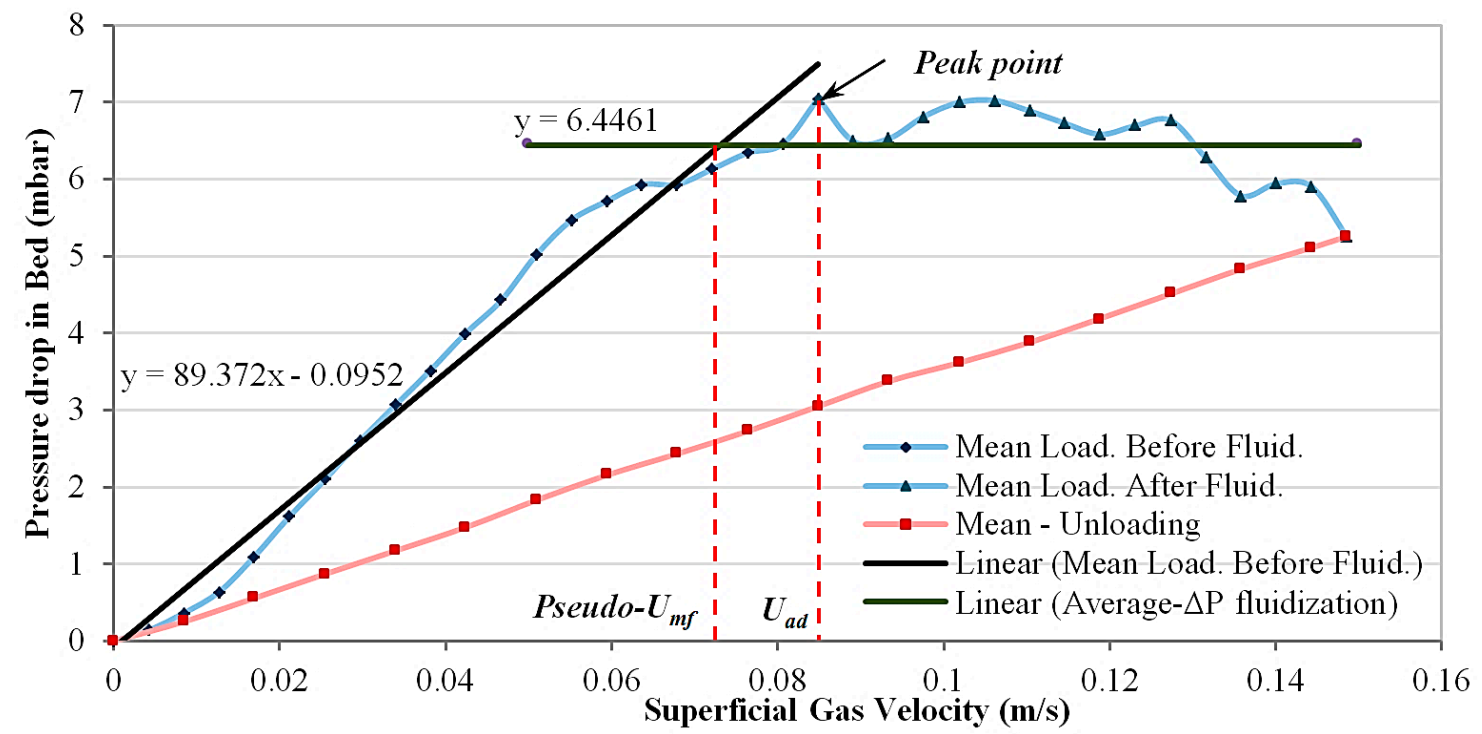

Figure 18. Mean value of $\Delta P_{b}\left(U_{s g}\right)$ when repeating fluidization tests for fluidization loading and unloading of mixed material-( $68 \%$ of ultra-fine $+32 \%$ of fine particles). 


\subsubsection{Bed Expansion Ratio}

To understand better the behaviour of different mixtures of materials during fluidization, Figure 19 shows the bed expansion ratio (\%) of the bed when increasing the superficial gas velocity. This figure shows that at the beginning of the unloading stage (right part of the figures), the height of the bed during loading conditions is always higher or equal than during unloading for a given value of the superficial gas velocity. During fluidization, due to the spouting particles from the channels, the height of the central part of the channel decreases and the height of its peripheral part increases. In addition, the location of the channels also changes when changing the superficial gas velocity. As a consequence, a non-level surface is observed. For this reason, an average height calculated over the whole surface (see Section 3 for the methodology) has been used as height in Figure 19.

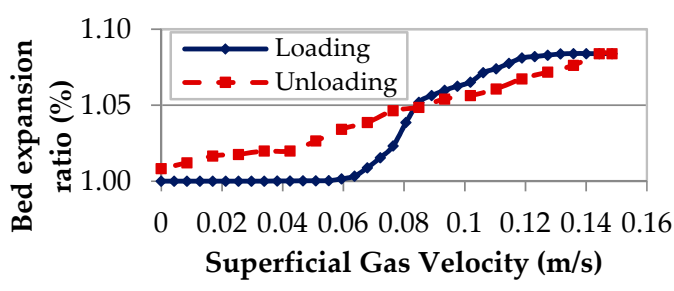

(a) MX-10 (100\% ultra-fine)

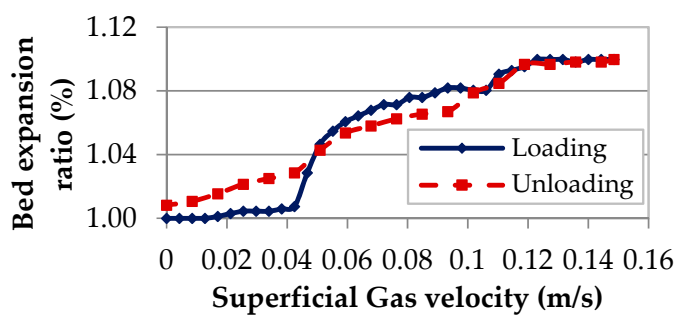

(c) $50 \%$ ultra-fine- $50 \%$ fine

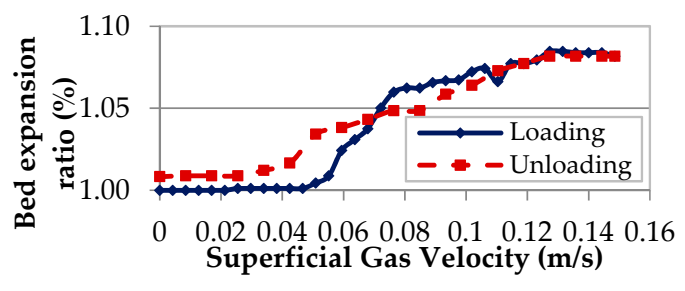

(b) $68 \%$ ultra-fine- $32 \%$ fine

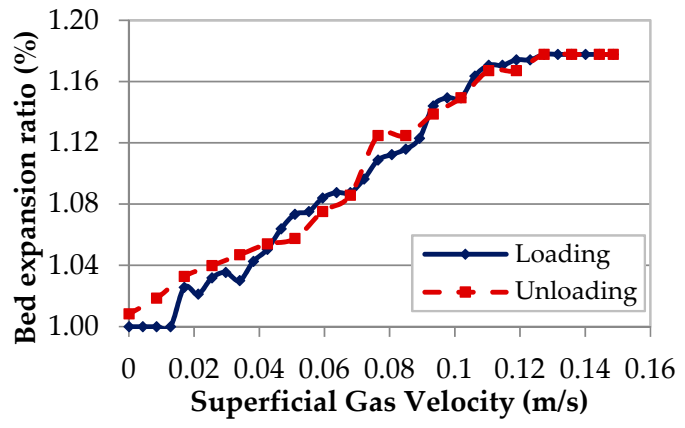

(d) $30 \%$ ultra-fine-70\% fine

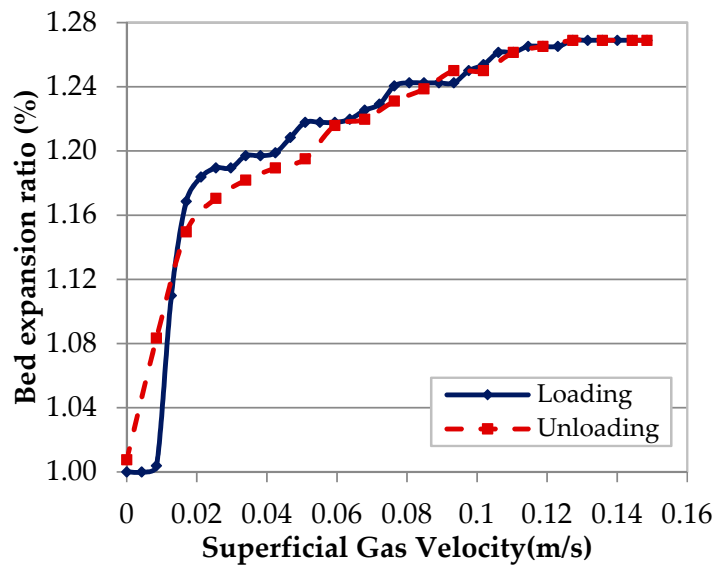

(e) MVT-100 (100\% fine)

Figure 19. Bed expansion ratio $\left(\Delta h_{b} / L_{0}\right.$, where $\Delta h_{b}$ and $L_{0}$ are the current and the initial height of the bed, respectively) as a function of superficial gas velocity for different mixtures of materials.

At lower superficial gas velocities (left part of the figures), the bed height for unloading is higher than for loading. It is noted that the loading and unloading curves cross each other at a velocity near the calculated pseudo- $U_{m f}$ for all mixtures. In addition, by increasing the percentage of ultra-fine particles in the mixture, the bed expansion ratio (\%) decreases and the total expansion of the bed after 
unloading increases. Table 4 shows the values for the bed expansion ratio (\%) and the total expansion of the bed for better comparison.

Table 4. The bed expansion ratio (\%) and the total bed expansion of the used powder mixtures.

\begin{tabular}{ccc}
\hline Mixture Material & Bed Expansion Ratio (\%) & Total Expansion of the Bed (mm) \\
\hline CALCIT MVT-100 & 126.89 & 0.51 \\
\hline $70 \%$ Fine-30\% Ultrafine & 117.77 & 0.5825 \\
\hline $50 \%$ Fine-50\% Ultrafine & 109.97 & 0.69 \\
\hline $32 \%$ Fine-68\% Ultrafine & 108.47 & 0.8333 \\
\hline CALCIT MX-10 & 108.40 & 0.9375 \\
\hline
\end{tabular}

\subsubsection{Aggregation States of Cohesive Powders}

For describing the observed behaviour, the fluidization of ultra-fine cohesive powders is studied first. Cohesive powders usually show three different states of aggregation, that is, individual particles (agglomerate-free), natural agglomerates, as well as fluidized agglomerates [2]. Due to the relative motion between ultra-fine particles, they form quasi-spherical agglomerates when kept in a container or during transfer to the fluidization column, which are named natural agglomerates. This kind of agglomerates is lightweight and breakable. Also, they have a relatively narrow size distribution.

Figure 20 shows the natural agglomerates of fine, ultra-fine and different mixtures of these two materials. The shape, size and structure of the formed natural agglomerates of each mixture have been captured by a KEYENCE digital microscope system VH-Z250R (real zoom lens from $250 \times$ to $2500 \times$ ).

These pictures taken from the microscope show that for fine particles, almost all of the particles are single particles with different shapes and sizes according to the size distribution of this material. The natural agglomerates of the mixture of $70 \%$ of fine and $30 \%$ of ultra-fine particles show some small agglomerates, mostly with fine particles in the core. This means that the ultra-fine powders stick to the surface of fine particles and form agglomerates. By increasing further the percentage of ultra-fine powders to 50,68 and 100 percent, thus increasing the value of cohesiveness, the size of natural agglomerates increases. The pictures also show that the sphericity of the agglomerates is increased when increasing the ultra-fine particles in the mixture.

After starting fluidization, in a competition between the transport of agglomerates by the gas flow and the cohesive forces between them, they become restructured regarding the number of constituent particles. They can be disintegrated into smaller agglomerates or even single particles. This new configuration of agglomerates is called fluidized agglomerates. Due to considerable cohesive forces between the agglomerate and peripheral adhered particles, some larger agglomerates may be created. When increasing the size of agglomerates due to high cohesive force between particles, more kinetic energy (superficial gas velocity) and larger forces (bed pressure drop) are needed to reach the disruption point and start fluidization (even partial). Therefore, due to the high intensity of cohesiveness, the maximum bed pressure drop (peak point) during fluidization process is expected to move toward a higher superficial gas velocity for pure ultra-fine powders, as confirmed by the present measurements.

Figure 21 shows the fluidized agglomerates formed in the ultra-fine powder fluidized bed for three different superficial gas velocities. Due to the sticking of the ultra-fine particles to the walls leading to the build-up of an opaque layer, a detailed optical analysis is not possible in general. However, these images reveal the general morphology of semi-spherical fluidized agglomerates. Considering the size distribution of the powders for this material $(<10 \mu \mathrm{m})$, all of the observed semi-spherical objects in this figure are the formed agglomerates during the fluidization process. The size of agglomerates varies from almost $3 \mathrm{~mm}$ at the bottom of the de-fluidized region to dozens of micrometres for the spouting agglomerates in the channel opening. The fluidized and de-fluidized zones are separated by red lines in each picture. 


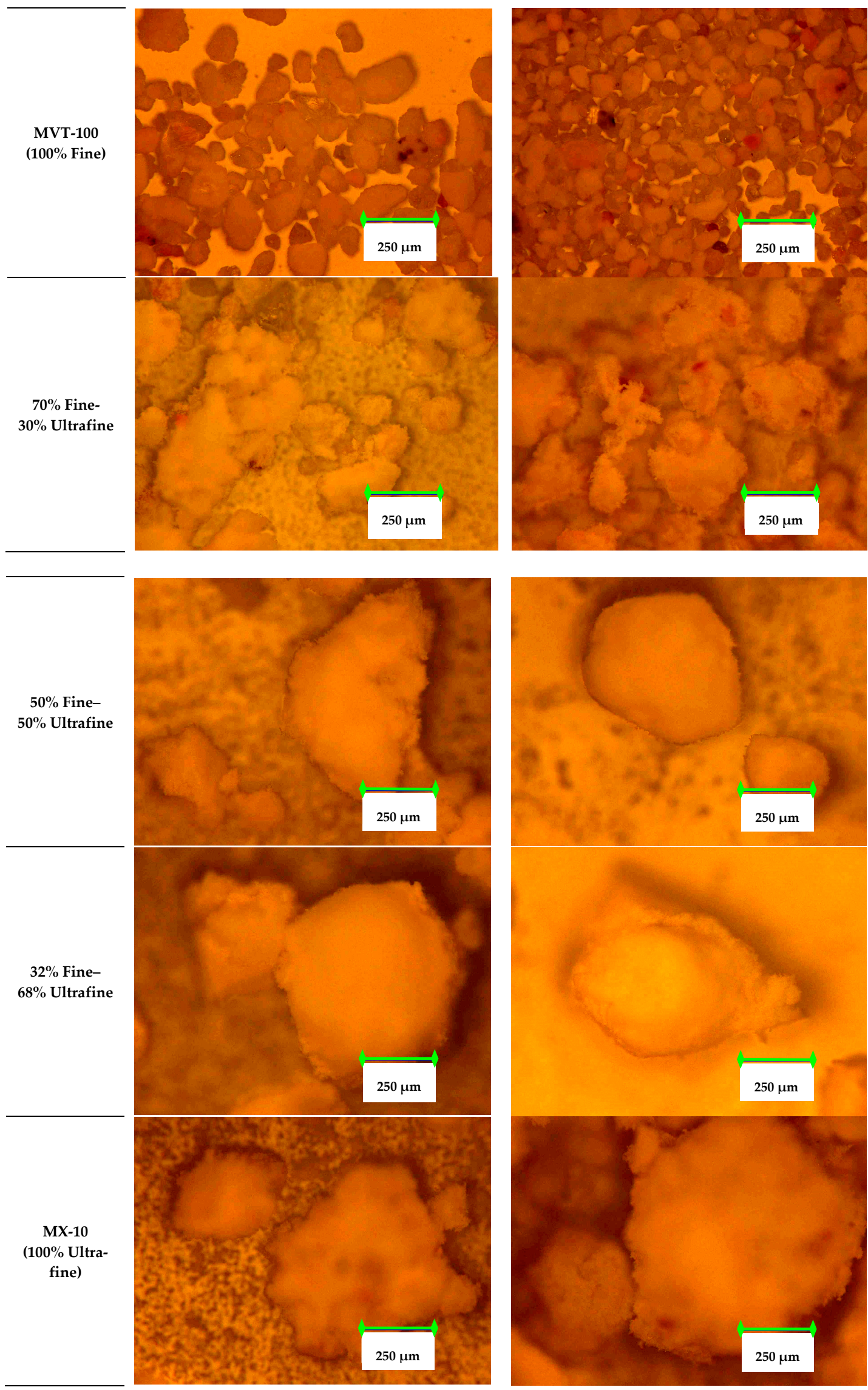

Figure 20. Pictures taken from the microscope for formed natural agglomerates on the microscope slides. Each row shows two exemplary pictures for each material or material mixtures. 


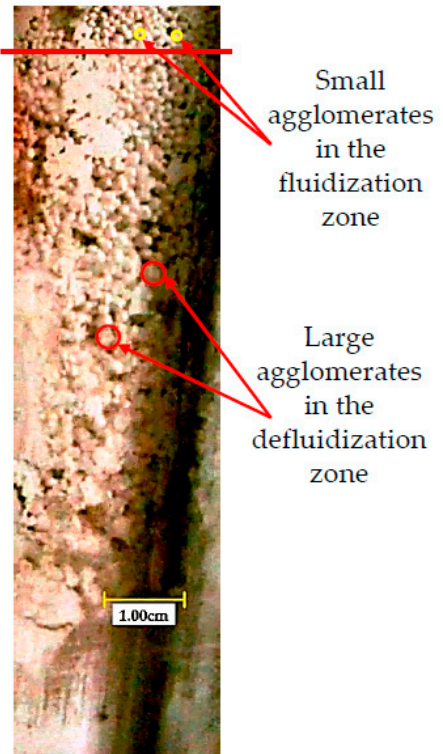

(a) $\mathrm{U}_{\mathrm{sg}}=11.46 \mathrm{~cm} / \mathrm{s}$

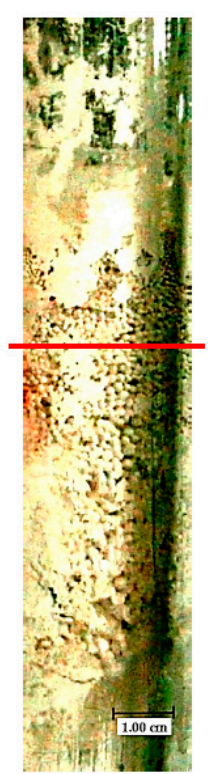

(b) $\mathrm{U}_{\mathrm{sg}}=11.88 \mathrm{~cm} / \mathrm{s}$

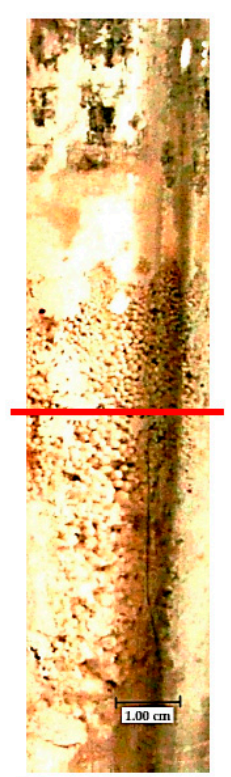

(c) $\mathrm{U}_{\mathrm{sg}}=12.31 \mathrm{~cm} / \mathrm{s}$

Figure 21. Cropped sections of an active channel near the wall during a fluidization test of ultra-fine material for three different values of superficial gas velocity. The red line is used as a separator of two fluidized and de-fluidized zones (Above the line: fluidized; Below the line: de-fluidized). (a) This figure is a zoomed-in capture for a better view of formed agglomerates at lower velocity, $11.46 \mathrm{~cm} / \mathrm{s}$; (b) The formed agglomerates for whole domain at $11.88 \mathrm{~cm} / \mathrm{s}$; (c) Changes in the agglomerates' size and shape as well as thickness of de-fluidized zone by increasing the superficial gas velocity to $12.31 \mathrm{~cm} / \mathrm{s}$.

\subsubsection{Effect of Mixing Fine and Ultra-Fine Materials on the Agglomerates}

Mixing fine particles with ultra-fine powders improves the fluidization behaviour of ultra-fine powders for two reasons. First, the smaller fine particles can form new agglomerates; that is, ultra-fine particles stick to the surface of fine particles to form some stable agglomerates. Baeyens et al. [46] reported that the ultra-fine powders adhere to larger particles, rather than they agglomerate with each other. Second, crushing and breaking of the formed agglomerates occurs due to friction or collisions; this is particularly frequent in the presence of larger fine particles [25] and changes the size distribution. Agglomerates containing fine particles are not necessarily bigger but can reach a far higher weight than those containing only ultra-fine powders. Therefore, they can get more kinetic energy and more easily disintegrate by collision or friction. Thus, the size of these agglomerates becomes smaller. After each collision, depending on agglomerate density, on the relative collision velocity, on the distance between agglomerates or particles, some new agglomerates are created. This process increases the variety of agglomerate sizes (leading to a wide size distribution for the formed agglomerates) and their structure becomes denser (as discussed before).

Shear cell tests already showed that the intensity of cohesiveness decreases when increasing the portion of fine particles (see Table 3). Thus, by increasing the percentage of fine particles in the mixture, the fluidization behaviour in such a mixture (partial fluidization) is further improved, so that the disruption point is reached at a lower superficial gas velocity and lower bed pressure drop. In parallel, by increasing the percentage of fine particles in the mixture, the probability of the breakage of agglomerates increases in two ways. First, forming some new agglomerates with fine particles in the core; these have more weight and more kinetic energy than the agglomerates formed during collisions by ultra-fine particles only. The second way is the existence of some larger fine particles (up to $200 \mu \mathrm{m}$ ) in the bed. The larger fine particles have a bulk density near to the particle density. Then, they have more weight and more kinetic energy than any agglomerates formed by finer particles.

A wide size distribution results in the smaller void sizes [40] and the enhanced fluidity [42]. This wide distribution increases the chance of filling the available voids between larger particles 
(agglomerates) by finer ones. Therefore, the size of micro-voids is decreased, hindering the growth of cracks between particle layers. In addition, decreasing the intensity of cohesiveness decreases the ability to form arches between particles [47], resulting in a denser mixture.

According to Geldart et al. [1], a strong intensity of cohesiveness leads to an increase in the number and size of micro-voids, as also described by Massimilla and Donsi [3]. Numerous horizontal and sloping cracks or channels form; then, the bed expands without true bubble formation. Conversely, decreasing the intensity of cohesiveness when increasing the number of fine particles decreases the size and number of micro-voids, limiting the growth of cracks and increasing the probability of small bubble formation. In fact, by decreasing the inter-particle forces, the small bubbles form, grow and disrupt the dense structure of the bed. Rising bubbles in the bed are the main reason for conversion of horizontal or sloping cracks to vertical channels. Thus, the formed cracks in the bed are converted much easier to vertical channels, leading to a further improvement in fluidization behaviour. In fact, this conversion increases the particles-air contact and forms the agglomerates.

For all mixtures, the observed fluidization is partial fluidization and the air flow does not fluidize the whole particle bed. Therefore, it is not necessary for the air to move the entire bed and overcome its weight. This fact can explain the decrease in the level of bed pressure drop at the peak point for mixtures containing a higher portion of fine particles, to lower values than the $P_{w b}$ of the bed.

On the other hand, the wide range of the size of agglomerates, as well as reduced cohesion level in the compositions containing more fine particles, lead to a denser structure (similar to the structure of fine particles only). Then, the bed resistance increases against the gas flow. In other words, by increasing the portion of fine particles in the mixture, the bed pressure drop corresponding to each superficial gas velocity increases (packed bed condition). Therefore, the slope of the $\Delta P_{b}$ versus $U_{s g}$ graph increases in the packed bed section of the loading curve.

However, for the case with $68 \%$ ultra-fines, increasing the portion of ultra-fine powders leads to increasing the inter-particle forces (Table 3 shows only $2 \%$ difference in the intensity of cohesiveness between this mixture and ultra-fine material only). This can explain the increase in the peak of bed pressure drop. The mixture containing $68 \%$ of ultra-fines has properties very close to pure ultra-fine powders; thus, it is conceivable that it mimics ultra-fine fluidization behaviour. For this mixture, due to increasing inter-particle forces as well as forming agglomerates with a more uniform size distribution, the mixture has a lower bulk density and higher porosity (proved by the bed initial height for the same weight of material). Therefore, in the packed bed condition, due to the lower bulk density and higher permeability, the bed pressure drop for each specified gas velocity is lower than for the two other mixtures; the slope of the loading curve is reduced. However, this mixture needs a higher bed pressure drop for disrupting and overcoming the inter-particle forces.

To estimate the size of the formed agglomerates in each part of the fluidization tests of different mixtures of materials, the Ergun equation (Equation (12)) along with Wen \& Yu equation (Equation (3)) can be used to calculate the mean value of agglomerates' size. Considering the Ergun equation for the linear part (packed bed condition) of the fluidization curve, the mean value of agglomerate size in the three conditions (1. the initial phase of loading (near-zero velocity), 2. at slightly higher gas velocities in the fixed bed condition of loading, as well as 3 . near to rest (near-zero velocity) state in the unloading condition), can be calculated as:

$$
d_{p}=\sqrt{\frac{150 \mu L_{0}(1-\varepsilon)^{2}}{\varepsilon^{3}} \frac{U_{s g}}{\Delta P_{b}}}
$$

In addition, using the Wen \& Yu equation, the agglomerate sizes can also be estimated at the fluidization point. Substituting the needed parameters in this equation, the mean value of agglomerates size can be obtained from

$$
d_{p}=0.00055546\left(U_{m f}^{2}+\sqrt{U_{m f}^{4}+3.696 U_{m f}}\right)
$$


In these equations, the calculated pseudo- $U_{m f}$ is used as $U_{m f}$. For the low-velocity condition, these equations predict slightly larger agglomerates for mixtures containing a higher portion of fine particles (it increases from 91 to $100 \mu \mathrm{m}$ ). On the contrary, at the minimum fluidization velocity point and due to increasing kinetic energy (increasing gas velocities), the mean value of agglomerates' size is decreased (from 274 to $154 \mu \mathrm{m}$ ) when increasing the portion of fine particles, as already discussed previously.

After starting channelling, the small channels grow to a bigger one when increasing further the gas velocity and two distinct regions are established; that is, fixed and fluidized (active channel) zones. When the gas velocity increases further, these zones alternate in an unsteady manner during the experiment. In some cases, this is accompanied by moving and bursting of bubbles.

Figures 16-18 also show that increasing the ultra-fine material in the mixture increases the hysteresis effect between loading and unloading curves. The hysteresis can be the result of the following three factors:

(a) the need for a greater force to overcome the cohesion forces between the particles,

(b) increase in the irreversible deformation of particulate materials in the fluidization process and

(c) energy dissipation during collisions or friction between particles or agglomerates.

According to Tomas [48]: "Obviously, the finer the particles the "softer" are the contacts and the more cohesive is the powder." It means that for ultra-fine particles, due to a high level of cohesive inter-particle forces and even without direct contact, there are some plastic, irreversible deformations for the particles close to each other. In the fluidization process, due to the kinetic energy provided by the fluidizing gas, the number of contact and collision increases. Therefore, due to softer contact behaviour, the irreversible deformations are higher for the mixtures with a higher proportion of ultra-fine particles. This induces a stronger hysteresis effect compared to mixtures with a lower amount of ultra-fine powders.

In addition to some irreversible deformation of ultra-fine particles due to cohesive forces, the formation and collapse of the channels and cracks in the powder bed and avalanching of different particle layers on each other can explain most of these irreversible deformations. The probability of irreversible deformation increases when increasing the proportion of ultra-fine particles.

\section{Conclusions}

In this paper, different fluidization tests were conducted for fine particles, ultra-fine particles and mixtures of these two materials in order to study the effect of the presence of ultra-fine particles on the fluidization of a fine-particle bed. The investigations concentrated on $30 \%, 50 \%$ and $68 \%$ (weight percentage) of ultra-fines; all show only partial fluidization. The fluidization behaviour of fine material (Geldart A) is characterized by an easy, aggregative (bubbling) and full fluidization. For fine material, experimental results also show smooth fluidization with a slight hysteresis effect.

When mixing with ultra-fine powders, the experimental results show that the presence of ultra-fine powders can change the full fluidization of fine particle bed severely. The measured physical properties (e.g., $\rho_{b}, c_{M}, d_{M}$ and $f f_{c}$ ) of the mixtures of fine and ultra-fine particles are close to those of ultra-fine powders only. Similar to ultra-fine powders, the fluidization behaviour of these mixtures is partial, non-reproducible, significantly different for each realization, and includes cracking, channelling and agglomeration. Initial conditions have significant impacts on fluidization behaviour. There are many fluctuations in the bed pressure drop when increasing gas velocity (loading process). Therefore, to have a better overview of fluidization process for these mixtures, the fluidization tests have been repeated and the mean value of the bed pressure drop for each gas velocity has been used for analysing the fluidization behaviour. When decreasing the fluidization air velocity (unloading curve), the change in the bed pressure drop shows an almost linear behaviour, corresponding to an approximately constant permeability.

Briefly, increasing the portion of ultra-fine powders in the fluidized material causes a delay in starting partial fluidization, an increase in the bed pressure drop, a delay in reaching the peak point, 
a decrease in the bed expansion ratio (\%), an increase in the total expansion of the bed after unloading as well as an increase in the hysteresis effect between loading and unloading curves. To understand these phenomena, the effect of mixing fine particles with cohesive ultra-fine powders and their roles in modifying the size distribution of agglomerates are discussed.

Author Contributions: A.K.M. and J.T. conceived and designed the experiments; A.K.M. performed the experiments; A.K.M. and D.T. analysed the data and wrote the initial draft of the manuscript; J.T., D.T., S.A. and A.B. assisted the experiment procedures; A.K.M., D.T., S.A., B.v.W. and A.B. reviewed and contributed to the final manuscript.

Funding: This work was funded by the German Research Foundation (DFG) within the research training group "Micro-Macro-Interactions in Structured Media and Particle Systems" (GRK 1554).

Conflicts of Interest: The authors declare no conflict of interest.

\section{List of Symbols and Notations}

\section{Greek symbols}

Void fraction of particle bed ()

$\varepsilon_{m f}$

$\vartheta_{g}$

Void fraction at minimum fluidization condition ()

$\mu_{g}$

Kinematic viscosity of fluid (gas) $\left(\mathrm{m}^{2} / \mathrm{s}\right)$

$\mu_{g} \quad$ Dynamic viscosity of fluid (gas) $(\mathrm{kg} / \mathrm{m} \cdot \mathrm{s})$

$\rho_{a g} \quad$ The density of agglomerate $\left(\mathrm{kg} / \mathrm{m}^{3}\right)$

$\rho_{f}, \rho_{g} \quad$ The density of the fluid or gas $\left(\mathrm{kg} / \mathrm{m}^{3}\right)$

$\rho_{p} \quad$ The density of particle $\left(\mathrm{kg} / \mathrm{m}^{3}\right)$

$\sigma \quad$ Normal stress $\left(\mathrm{kg} / \mathrm{m} \cdot \mathrm{s}^{2}\right)$

$\tau \quad$ Shear stress $\left(\mathrm{kg} / \mathrm{m} \cdot \mathrm{s}^{2}\right)$

$\varphi_{i} \quad$ The angle of internal friction ()

$\varphi_{s} \quad$ Particle sphericity ()

Roman symbols

A

Ae

Ar

c

$\mathrm{d}_{50}$

$d_{p}$

$\mathrm{d}_{\mathrm{ST}}$

$E_{c}$

$E_{G}$

$\mathrm{F}_{\mathrm{C}}$

$\mathrm{F}_{\mathrm{g}}$

$f f_{c}$

$g$

$\Delta h_{b}$

$\Delta h_{w}$

$k$

$L_{0}$

$m_{S}$

$P_{a}$

$\Delta P_{b}$

$\Delta P_{D}$

Re

$\operatorname{Re}_{m f}$

$U_{s g}$

$U_{m f}$

$\dot{V}$

$w$
Bed cross-section area $\left(\mathrm{m}^{2}\right)$

Particle agglomeration number ()

Archimedes number ()

Intensity of cohesiveness $\left(\mathrm{kg} / \mathrm{m} \cdot \mathrm{s}^{2}\right)$

Mass-mean particle diameter $(\mathrm{m})$

Particle diameter $(\mathrm{m})$

Sauter mean diameter $(\mathrm{m})$

Cohesive effect on minimum fluidization velocity ()

Gravitational effect on minimum fluidization velocity ()

Cohesive force between agglomerates and their peripheral adhered powders $\left(\mathrm{kg} \cdot \mathrm{m} / \mathrm{s}^{2}\right)$

The gravity of the peripheral adhered spherical powders $\left(\mathrm{kg} \cdot \mathrm{m} / \mathrm{s}^{2}\right)$

Bulk solid flowability ()

Gravity acceleration $\left(\mathrm{m} / \mathrm{s}^{2}\right)$

The height of the bed $(\mathrm{m})$

The pressure drop across the bed $(\mathrm{m})$

Permeability $\left(\mathrm{m}^{2}\right)$

Initial bed height $(\mathrm{m})$

The total mass of particle bed $(\mathrm{kg})$

Gage pressure within the apparatus $\left(\mathrm{kg} / \mathrm{m} \cdot \mathrm{s}^{2}\right)$

Bed pressure drop $\left(\mathrm{kg} / \mathrm{m} \cdot \mathrm{s}^{2}\right)$

The pressure drop of the gas distributor $\left(\mathrm{kg} / \mathrm{m} \cdot \mathrm{s}^{2}\right)$

Reynolds number ()

Reynolds number at minimum fluidization velocity ()

Superficial gas velocity $(\mathrm{m} / \mathrm{s})$

Minimum fluidization velocity $(\mathrm{m} / \mathrm{s})$

The volumetric flow rate of the fluid passing through a porous medium $\left(\mathrm{m}^{3} / \mathrm{s}\right)$

The weight fraction of a sample particle in a mixture () 


\section{References}

1. Geldart, D.; Harnby, N.; Wong, A.C. Fluidization of cohesive powders. Powder Technol. 1984, 37, $25-37$. [CrossRef]

2. Wang, Z.; Kwauk, M.; Li, H. Fluidization of fine particles. Chem. Eng. Sci. 1998, 53, 377-395. [CrossRef]

3. Massimilla, L.; Donsì, G. Cohesive forces between particles of fluid-bed catalysts. Powder Technol. 1976, 15, 253-260. [CrossRef]

4. Dry, R.J.; Judd, M.R.; Shingles, T. Two-phase theory and fine powders. Powder Technol. 1983, 34, $213-223$. [CrossRef]

5. Shaul, S.; Rabinovich, E.; Kalman, H. Typical fluidization characteristics for Geldart's classification groups. Part. Sci. Technol. 2014, 32, 197-205. [CrossRef]

6. Valverde Millán, J.M. Fluidization of Fine Powders; Particle Technology Series; Springer: Dordrecht, The Netherlands, 2013; Volume 18, ISBN 978-94-007-5586-4.

7. Geldart, D. Types of gas fluidization. Powder Technol. 1973, 7, 285-292. [CrossRef]

8. Ajbar, A.; Alhumazi, K.; Asif, M. Improvement of the fluidizability of cohesive powders through mixing with small proportions of group A particles. Can. J. Chem. Eng. 2008, 83, 930-943. [CrossRef]

9. Dechsiri, C. Particle Transport in Fluidized Beds. Ph.D. Thesis, UMCG Research Database. University of Groningen, Groningen, The Netherlands, 2004.

10. Abrahamsen, A.R.; Geldart, D. Behaviour of gas-fluidized beds of fine powders part I. Homogeneous expansion. Powder Technol. 1980, 26, 35-46. [CrossRef]

11. Yang, W.-C. Handbook of Fluidization and Fluid-Particle Systems; Marcel Dekker, Inc.: New York, NY, USA, 2003; pp. 1-850, ISBN 082470259X.

12. Rumpf, H. Die Wissenschaft des Agglomerierens. Chem. Ing. Tech. 1974, 46, 1-11. [CrossRef]

13. Valverde Millán, J.M. Fluidization of Fine Powders: Cohesive versus Dynamic Aggregation. In The 14th International Conference on Fluidization-From Fundamentals to Products; ECI Symposium Series; Springer Netherlands: Dordrecht, The Netherlands, 2013.

14. Horio, M. Binderless granulation-Its potential, achievements and future issues. Powder Technol. 2003, 130, 1-7. [CrossRef]

15. Barletta, D.; Poletto, M. Aggregation phenomena in fluidization of cohesive powders assisted by mechanical vibrations. Powder Technol. 2012, 225, 93-100. [CrossRef]

16. Xu, C.; Zhu, J. Experimental and theoretical study on the agglomeration arising from fluidization of cohesive particles-Effects of mechanical vibration. Chem. Eng. Sci. 2005, 60, 6529-6541. [CrossRef]

17. Mawatari, Y.; Koide, T.; Tatemoto, Y.; Uchida, S.; Noda, K. Effect of particle diameter on fluidization under vibration. Powder Technol. 2002, 123, 69-74. [CrossRef]

18. Mawatari, Y.; Hamada, Y.; Yamamura, M.; Kage, H. Flow pattern transition of fine cohesive powders in a gas-solid fluidized bed under mechanical vibrating conditions. Procedia Eng. 2015, 102, 945-951. [CrossRef]

19. Meili, L.; Daleffe, R.V.; Freire, J.T. Fluid Dynamics of Fluidized and Vibrofluidized Beds Operating with Geldart C Particles. Chem. Eng. Technol. 2012, 35, 1649-1656. [CrossRef]

20. Zhu, C.; Liu, G.; Yu, Q.; Pfeffer, R.; Dave, R.N.; Nam, C.H. Sound assisted fluidization of nanoparticle agglomerates. Powder Technol. 2004, 141, 119-123. [CrossRef]

21. Guo, Q.; Liu, H.; Shen, W.; Yan, X.; Jia, R. Influence of sound wave characteristics on fluidization behaviors of ultrafine particles. Chem. Eng. J. 2006, 119, 1-9. [CrossRef]

22. Shabanian, J.; Jafari, R.; Chaouki, J. Fluidization of Ultrafine Powders. Int. Rev. Chem. Eng. 2012, 4, 16-50.

23. Zhu, X.; Zhang, Q.; Huang, C.; Wang, Y.; Yang, C.; Wei, F. Validation of surface coating with nanoparticles to improve the flowability of fine cohesive powders. Particuology 2017, 30, 53-61. [CrossRef]

24. Zhou, T.; Li, H. Effects of adding different size particles on fluidization of cohesive particles. Powder Technol. 1999, 102, 215-220. [CrossRef]

25. Duan, H.; Liang, X.; Zhou, T.; Wang, J.; Tang, W. Fluidization of mixed $\mathrm{SiO}_{2}$ and $\mathrm{ZnO}$ nanoparticles by adding coarse particles. Powder Technol. 2014, 267, 315-321. [CrossRef]

26. Song, L.; Zhou, T.; Yang, J. Fluidization behavior of nano-particles by adding coarse particles. Adv. Powder Technol. 2009, 20, 366-370. [CrossRef]

27. Ajbar, A.; Alhumaizi, K.; Ibrahim, A.; Asif, M. Hydrodynamics of gas fluidized beds with mixture of group D and B particles. Can. J. Chem. Eng. 2002, 80, 281-288. [CrossRef] 
28. Scala, F.; Cammarota, A.; Chirone, R.; Salatino, P. Comminution of Limestone during Batch Fluidized-Bed Calcination and Sulfation. AIChE J. 1997, 43, 363-373. [CrossRef]

29. Kamranian Marnani, A.; Idowu, R.; Bück, A.; Antonyuk, S.; Thévenin, D.; Tomas, J. Classification of ultra-fine adhesive particles at fine cohesive powders. In Proceedings of the 12th International Conference on Bulk Materials Storage, Handling and Transportation (ICBMH 2016), Darwin, Australia, 11-14 July 2016.

30. Tomas, J. The mechanics of dry, cohesive powders. Powder Handl. Process. 2003, 15, 296-314.

31. Rabinovich, E.; Kalman, H. Flow regime diagram for vertical pneumatic conveying and fluidized bed systems. Powder Technol. 2011, 207, 119-133. [CrossRef]

32. Shaul, S.; Rabinovich, E.; Kalman, H. Generalized flow regime diagram of fluidized beds based on the height to bed diameter ratio. Powder Technol. 2012, 228, 264-271. [CrossRef]

33. Yang, W.-C. Fluidization, Solids Handling, and Processing: Industrial Applications; Noyes Publications: Westwood, NJ, USA, 1998; ISBN 0815514271.

34. Ergun, S. Fluid flow through packed columns. Chem. Eng. Prog. 1952, 48, 89-94.

35. Wen, C.Y.; Yu, Y.H. A generalized method for predicting the minimum fluidization velocity. AIChE J. 1966, 12, 610-612. [CrossRef]

36. Grace, J.R. Fluidized-bed hydrodynamics. In Handbook of Multiphase Systems; Hemisphere: Washington, DC, USA, 1982; ISBN 978-0070284609.

37. Leva, M. Fluidization; McGraw-Hill: New York, NY, USA, 1959.

38. Xu, C.C.; Zhu, J. Prediction of the Minimum Fluidization Velocity for Fine Particles of Various Degrees of Cohesiveness. Chem. Eng. Commun. 2008, 196, 499-517. [CrossRef]

39. Turki, D.; Fatah, N. Behavior and fluidization of the cohesive powders: Agglomerates sizes approach. Braz. J. Chem. Eng. 2008, 25, 697-711. [CrossRef]

40. Sun, G.; Grace, J.R. Effect of particle size distribution in different fluidization regimes. AIChE J. 1992, 38, 716-722. [CrossRef]

41. Khoe, G.K.; Ip, T.L.; Grace, J.R. Rheological and fluidization behaviour of powders of different particle size distribution. Powder Technol. 1991, 66, 127-141. [CrossRef]

42. Gauthier, D.; Zerguerras, S.; Flamant, G. Influence of the particle size distribution of powders on the velocities of minimum and complete fluidization. Chem. Eng. J. 1999, 74, 181-196. [CrossRef]

43. Sun, G. Influence of particle size distribution on the performance of fluidized bed reactors. Can. J. Chem. Eng. 1991, 69, 207. [CrossRef]

44. Dahneke, B. Particle Bounce or Capture-Search for an Adequate Theory: I. Conservation-of-Energy Model for a Simple Collision Process. Aerosol Sci. Technol. 1995, 23, 25-39. [CrossRef]

45. Olivieri, G.; Marzocchella, A.; Salatino, P. Segregation of fluidized binary mixtures of granular solids. AIChE J. 2004, 50, 3095-3106. [CrossRef]

46. Baeyens, J.; Geldart, D.; Wu, S.Y. Elutriation of fines from gas fluidized beds of Geldart A-type powders-Effect of adding superfines. Powder Technol. 1992, 71, 71-80. [CrossRef]

47. Valverde, J.M.; Castellanos, A. Compaction of fine powders: From fluidized agglomerates to primary particles. Granul. Matter 2007, 9, 19-24. [CrossRef]

48. Tomas, J. Product design of cohesive powders-Mechanical properties, compression and flow behavior. Chem. Eng. Technol. 2004, 27, 605-618. [CrossRef]

(C) 2019 by the authors. Licensee MDPI, Basel, Switzerland. This article is an open access article distributed under the terms and conditions of the Creative Commons Attribution (CC BY) license (http://creativecommons.org/licenses/by/4.0/). 